\title{
DetecÇÃo de Microrganismos Cariogênicos em Bráquetes Metálicos, Com ou Sem Utilização de Agente Antimicrobiano, PELA TÉCNICA CHECKERBOARD DNA-DNA HYBRIDIZATION- ESTUDO IN VIVO.
}

Dissertação apresentada à Faculdade de Odontologia de Ribeirão Preto da Universidade de São Paulo, para obtenção do Grau de Mestre em Odontopediatria.

Orientador: Prof. Dr. Paulo Nelson Filho 
Olmedo, Lourdes Yanissely García

Detecção de microrganismos cariogênicos em bráquetes metálicos, com ou sem utilização de agente antimicrobiano, pela técnica Checkerboard DNA-DNA Hybridization - Estudo in vivo. Ribeirão Preto, 2009.

56p. : il. ; $30 \mathrm{~cm}$

Dissertação de Mestrado, apresentada à Faculdade de Odontologia de Ribeirão Preto/USP - Programa: Odontopediatria.

Orientador: Nelson-Filho, Paulo

1. Checkerboard DNA-DNA Hybridization. 2. Clorexidina. 3. Bráquetes ortodônticos. 4. Streptococcus mutans. 5. Streptococcus sobrinus. 6. Lactobacillus casei. 7. Lactobacillus acidophilus. 


\section{Detecção de Microrganismos Cariogênicos em Bráquetes \\ Metálicos, Com ou Sem Utilização de Agente \\ Antimicrobiano, Pela TéCNica CheCKERBoARd DNA-DNA \\ HYBRIDIZATION - ESTUDO IN VIVO}

Dissertação apresentada à Faculdade de Odontologia de Ribeirão Preto da Universidade de São Paulo, para obtenção do Grau de Mestre em Odontopediatria.

Data da defesa:

\section{Banca Examinadora}

Prof. Dr.

Julgamento: Assinatura:

Prof. Dr.

Julgamento: Assinatura:

Prof. Dr.

Julgamento: Assinatura: 


\section{Dedico este Trabalho,}

Ao meu Pai Omar Eugene García, que hoje não se encontra mais entre nós, pelo estimulo e amor incondicional. Por ter reconhecido minha importância em sua vida, nos seus últimos dias. Dedico esta vitória ao senhor.

A Deus,

Por me guiar com sua luz celeste, pela segurança em cada atitude tomada e por sentir sua presença em cada acontecimento de minha vida.

Aos meus pais Omar e Lourdes,

Por sempre terem confiado em minhas decisões, por mais incertas que fossem, e pelo apoio constante.

À minha Irmã Karen

Por todo seu esforço e dedicação, inclusive durante a doença de meu pai. Sem o seu apoio eu não teria continuado meus estudos. 


\section{Agradecimentos EspeCiais}

Ao Prof. Dr. Paulo Nelson Filho

Por sua inteligência, honestidade e vocação de professor e pesquisador. Por seu

exemplo de seriedade, dedicação e amor à pesquisa e seu incondicional apoio nos momentos mais dificeis da minha a vida.

À Prof. Dra. Lea Assed Bezerra da Silva

Por sua ajuda na tomada de decisões corretas e por me oferecer esta grande oportunidade em minha carreira profissional.

Ao Niels F. Hansen

Por todo seu carinho durante estes dois anos e por todo o incentivo em minha carreira. 
À Faculdade de Odontologia de Ribeirão Preto da Universidade de São Paulo, na pessoa do atual Diretor Prof. Dr. Osvaldo Luiz Bezzon e Vice-Diretor Prof. Dr. Valdemar Mallet da Rocha Barros.

À Coordenação do Programa de Pósgraduação em Odontopediatria da Faculdade de Odontologia de Ribeirão Preto da Universidade de São Paulo, na pessoa da coordenadora Prof. Dra. Léa Assed Bezerra da Silva e do vicecoordenador Prof. Dr. Paulo Nelson Filho, pela oportunidade de participar deste conceituado programa de PósGraduação, me permitindo vislumbrar perspectivas diferentes em minha vida.

A Prof. Dra. Izabel Yoko Ito, Pela honra de me permitir compartilhar de sua imensa sabedoria e bondade. pessoa que me impressionou com sua incansável dedicação, dinamismo e perseverança e por permitir-nos trabalhar em seu laboratorio.

À Prof. Dra. Maria Conceição Pereira Saraiva, pelo valioso auxilio e orientação na análise estatística dos resultados, não medindo esforços para me auxiliar. Seus ensinamentos foram mais do que acadêmicos. Muito Obrigada.

Às Profas. Dras. Magda Gomes Feres e Luciane Cristina de Figueredo, do Laboratório de Pesquisa em Odontologia II, Microbiologia, Imunologia e Biologia Molecular da Universidade de Guarulhos, e à Técnica de Laboratório Izilvania, pela contribuição no processamento do DNA das amostras e pela realização da parte laboratorial da técnica checkerboard DNA-DNA Hybridization.
Às minhas companheiras Marcela C. D. Andrucioli Soato, Patricia Alves Ferreira Amato e Marcela Perdiza, pela colaboração na realização da parte exterimental desse trabalho, pela cumplicidade e disposição.

Ao meu amigo Frederik Cristhoper Hansen Reyes, por colocar as palarras certas no momento indicado. "Cuando sientas cansancio piensa en los niños que estan esperando de ti .. y de lo que tú puedes hacer por ellos".

À Profa. Dra. Sada Assed, Profa. Dra. Aldevina Campos de Freitas, Profa. Dra. Maria Cristina Borsatto, Profa. Dra. Alexandra Mussolino Queiroz, Profa. Dra. Kranya Victória Diaz Serrano, Profa. Dra. Raquel Assed Bezerra da Silva e Dra. Gisele Faria, da disciplina de Odontopediatria da Faculdade de Odontologia de Ribeirão Preto - USP, pela orientação constante e experiências compartilhadas.

Aos docentes da Disciplina de Ortodontia da Faculdade de Odontologia de Ribeirão Preto - USP, Dra. Mirian Aiko Nakane Matsumoto, Dr. Adilson Thomazinho, Dra. Maria Bernadete Sasso Stuani, Dr. José Tarcísio Lima Ferreira e Dra. Carla Enoki Itikawa, pela amizade e agradável convivencia.

A Isabel Cristina Galino Sola e à Regiane Cristina Moi Sacilotto, da seção do Pos-Graduação da FORPIUSP, pela atenção que sempre me dispensaram.

Ao Marco Antonio dos Santos, Técnico de Laboratório do Departamento de Clinica Infantil, Odontologia Preventiva e Social da FORPIUSP, por sua dedicação, paciência e ajuda constante. 
Às funcionÁrias Fátima Aparecida Jacinto Daniel, Niva Ruggiero, Micheli Cristina Leite Rovanholo e Filomena Lelli Placciti, do Departamento de Cinica Infantil, Odontologia Preventiva e Social da FORPIUSP, pela confiança, disponibilidade e amizade.

Às minhas grandes Amigas Ana Elisa Costa Kiszewski e Flavia Caccavari de Argentina, por todo sell amor $e$ carinho.

À minha tia Doris Acosta de Olmedo, a minha eterna gratidão pelo carinho e lealdade mostrada à minha familia.

Às pós-graduandas Marta Contente, Cristina Bueno Brandão, Vanessa Bernardini Maldonado, Olivia Verardo e Marcela Perdiza.

A todos da Casa 13, pelos momentos compartilhados e amizade que, sem dúvida, colaboraram com o meu desenvolvimento. Especialmente a Mirko Alva, Lucas Nonato Oliveira, Iraci de Souza João e Cynthia Rustiguel Barbosa, meus mais sinceros agradecimentos.

Ao Francisco Leomagno Lima dos Santos, padre da Capela Teresa da Vila, pelos momentos de oração $e$ reencontro com nosso Senhor.

A amiga Thais Milena e seus pais, pelas horas de companhia e acolhida em sua casa.

Ao CNPg, pela bolsa concedida e pelo apoio financeiro ao Projeto.

A todos gue, de alguma forma, contriburam para a concretizaça dessa pesguisa. 
Olmedo, LYG. Detecção de microrganismos cariogênicos em bráquetes metálicos, com ou sem utilização de agente antimicrobiano, pela técnica Checkerboard DNA-DNA Hybridization - Estudo in vivo. [dissertação]. Ribeirão Preto: FORP - Universidade de São Paulo; 2009.

O objetivo do presente estudo clínico randomizado foi avaliar in vivo, por meio da técnica de biologia molecular Checkerboard DNA-DNA Hybridization: 1) A contaminação de bráquetes metálicos por 4 espécies bacterianas de microrganismos cariogênicos (Streptococcus mutans, Streptococcus sobrinus, Lactobacillus casei e Lactobacillus acidophilus); e 2) A eficácia da utilização do gluconato de clorexidina a $0,12 \%$ (Periogard $^{\circledR}$ ) sob a forma de bochechos, sobre esses microrganismos. Participaram do estudo 39 pacientes de 11 a 33 anos de idade, em tratamento com aparelho ortodôntico fixo, nos quais foram colados 2 bráquetes metálicos novos, nos pré-molares. Os pacientes do Grupo Controle $(n=20)$ foram orientados a fazer 2 bochechos semanais com solução placebo, durante 30 dias. Os pacientes do Grupo Experimental $(n=19)$ foram orientados a fazer bochechos com solução à base de gluconato de clorexidina a $0,12 \%$ (Periogard $\left.{ }^{\circledR}\right)$, da mesma forma que o grupo Controle. Decorridos 30 dias, os 2 bráquetes foram removidos de cada paciente e processados para detecção das 4 cepas bacterianas, pela técnica Checkerboard DNADNA Hybridization. Os resultados obtidos foram analisados por meio do teste nãoparamétrico de Kruskal-Wallis, utilizando o software SAS (Statistical Analysis System). O nível de significância adotado foi de 5\%. De acordo com os resultados obtidos, observou-se que $S$. mutans, S. sobrinus, L. casei e L. acidophilus foram detectados em $100 \%$ das amostras dos bráquetes de ambos os grupos. No entanto, os bráquetes do grupo Controle encontravam-se mais densamente contaminados por $S$. mutans e $S$. sobrinus $(p<0,01)$. No grupo Experimental, embora as quantidades de $S$. mutans, $S$. sobrinus, L. casei e L. acidophilus tenham sofrido redução numérica após o uso dos bochechos com solução de gluconato de clorexidina a 0,12\%, a comparação com os valores observados no grupo Controle evidenciou diferença estatisticamente significante apenas para $S$. mutans $(p=0,03)$. Concluiu-se que os bochechos com solução de gluconato de clorexidina a $0,12 \%$ podem ser úteis, na prática clínica, com a finalidade de reduzir os níveis de microrganismos cariogênicos, em pacientes portadores de aparelhos ortodônticos fixos. 


\section{ABstract}

Olmedo, LYG. Detection of cariogenic microorganisms on metallic brackets in vivo, with or without use of an antimicrobial agent by the checkerboard DNA-DNA hybridization technique [dissertação]. Ribeirão Preto: FORP - Universidade de São Paulo; 2009.

The purpose of this randomized clinical study was to evaluate in vivo, by the checkerboard DNA-DNA hybridization biomolecular technique: 1) The contamination of metallic brackets by four cariogenic bacterial strains (Streptococcus mutans, Streptococcus sobrinus, Lactobacillus casei and Lactobacillus acidophilus); and 2) The efficacy of $0.12 \%$ chlorhexidine gluconate mouthrinses (Periogard ${ }^{\circledR}$ ) against these microorganisms. Thirty-nine 11-33-year-old patients under treatment with fixed orthodontic appliances were enrolled in the study and had 2 new metallic brackets bonded to the premolars. For the patients of the control group $(n=20)$, mouthrinses with a placebo solution were prescribed twice a week during 30 days. The patients randomized to the experimental group $(n=19)$ were instructed to use a $0.12 \%$ chlorhexidine gluconate solution (Periogard ${ }^{\circledR}$ ) as an oral rinse twice a week during 30 days, in the same way as in control group. After this period, the 2 brackets were removed from each patient and processed for detection of the 4 bacterial strains by checkerboard DNA-DNA hybridization. The obtained data were analyzed statistically by the non-parametric Kruskal-Wallis test using the SAS (Statistical Analysis System) software. A level of significance of $5 \%$ was set for all analysis. S. mutans, S. sobrinus, L. casei and L. acidophilus were detected in $100 \%$ of the samples from brackets of both groups. However, the brackets of the control group were more heavily contaminated by $S$. mutans and $S$. sobrinus $(p<0.01)$. In the experimental group, although S. mutans, S. sobrinus, L. casei and L. acidophilus counts decreased after rinsing with the $0.12 \%$ chlorhexidine gluconate solution, the comparison with the values obtained in the control group showed statistically significant difference only for S. mutans $(p=0.03)$. In conclusion, the use of $0.12 \%$ chlorhexidine gluconate mouthrinses can be useful in clinical practice to reduce the levels of cariogenic microorganisms in patients under treatment with fixed orthodontic appliances. 


\section{SUMÁRIO}

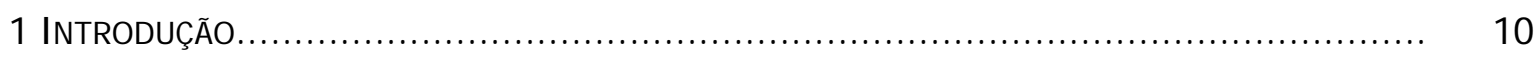

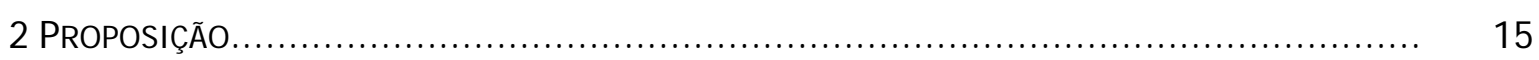

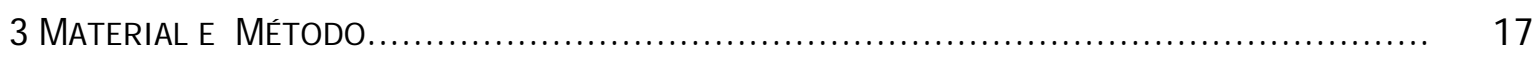

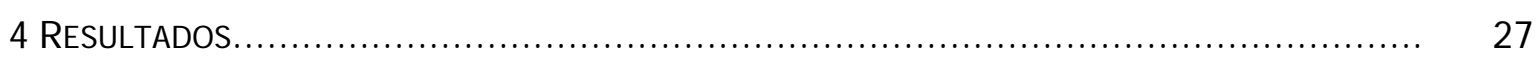

5 DISCUSSÃO

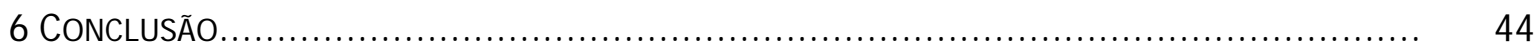

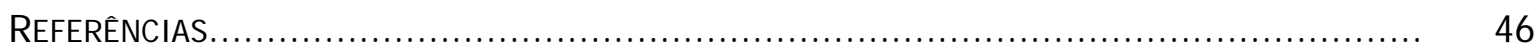

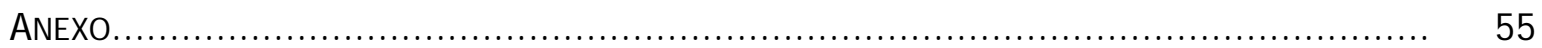


1 INTRODUÇÃO

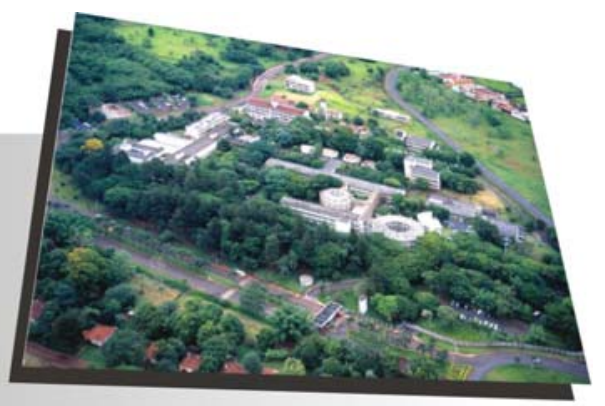




\section{】NTRODUÇão}

O tratamento ortodôntico por meio do uso de aparelhos fixos e removíveis promove alterações específicas no meio bucal (Anhoury et al., 2002; Brusca et al., 2007), incluindo redução do pH, aumento no acúmulo de biofilme dental (Gorelick et al., 1982; Naranjo et al., 2006) e elevação dos níveis salivares de microrganismos (Rosenbloom e Tinanoff, 1991; Sandham et al., 1992; Leung et al., 2006; Sari e Birinci, 2007).

Esse fato ocorre pois os aparelhos ortodônticos são compostos por uma variedade de materiais sólidos e elásticos (Steinberg e Eyal, 2004), com superfícies irregulares incluindo bráquetes, acrílico, bandas, fios e outros acessórios, as quais funcionam como áreas de retenção de biofilme bacteriano (Leung et al., 2006; Lessa et al., 2007; Ahn et al., 2007; Magno et al., 2008). Além disso, dificultam a higienização (Olympio et al., 2006; Faltermeier et al., 2008) e auto-limpeza mecânica efetuada pela saliva e pela movimentação da musculatura (Rosenbloom e Tinanoff, 1991), elevando o risco à cárie dental e a doenças periodontais (Artun e Brobakken, 1986; Anhoury et al., 2002; Sudjalim et al., 2007; Consolaro e Consolaro, 2008; Lo et al., 2008).

A cárie dental é considerada uma doença causada por bactérias desde 1890, quando Miller apresentou a teoria químico-parasitária. No entanto, somente em 1924, Clarke identificou os Streptococcus mutans sendo estes, atualmente, considerados os agentes etiológicos primários da cárie dental (Adjic et al., 2002; McNeill e Hamilton, 2003). Em 2002, o genoma dos S. mutans foi seqüenciado (Adjic et al., 2002), exatamente 49 anos após a publicação da descoberta da estrutura da molécula do DNA pelos físicos Francis Harry Compton Crick e James Dewey Watson, na renomada revista Nature (Silveira, 2003). O conhecimento mais aprofundado da complexidade e especificidade genética desses microrganismos pode possibilitar que, em um futuro próximo, sejam desenvolvidos novos agentes antimicrobianos, com abordagens inovadoras, visando a prevenção e o tratamento da cárie dental.

O grupo mutans (Hardie, 1986) é composto por várias espécies de microrganismos, incluindo S. mutans, S. sobrinus, S. cricetii, S. ratii, S. oris 
ratii, S. ferus, S. macacae e S. downei. Dentre essas espécies, as 2 mais comumente isoladas da espécie humana (Hofling et al., 1999) e mais diretamente envolvidas no processo da cárie dental são os $S$. mutans e os $S$. sobrinus (Loesche, 1986; Fejerskov e Kidd, 2005; Saito et al., 2009). A detecção desses microrganismos no biofilme dental e na saliva pode predizer 0 risco de cárie e servir para o monitoramento da atividade de cárie (Fontana, 2006).

Em humanos, os S. mutans são mais frequentemente isolados que os S. sobrinus (Loesche, 1986). Os S. sobrinus são mais sacarose-dependentes que os S. mutans (Gibbons et al., 1986) e apresentam maior capacidade de produção de ácidos (De Soet et al., 1989; Saito et al., 2009). Além disso, a coexistência de $S$. mutans e $S$. sobrinus parece ser um importante fator no desenvolvimento da cárie dental (Lindquist e Emilson, 1991), uma vez que quando ambas as espécies estão presentes na cavidade bucal, evidencia-se maior experiência de cárie nos indivíduos que quando se detecta apenas $S$. mutans (Köhler e Bjarnason, 1987; Seki et al., 2006).

Por outro lado, os Lactobacillus colonizam a cavidade bucal no primeiro ano de vida (Badet e Thebaud, 2008) e estão presentes na saliva, no dorso da língua, nas membranas mucosas, no palato duro e no biofilme dental (Socransky e Maganiello, 1971; Straetemans et al., 1998). A presença de Lactobacillus na cavidade bucal depende, dentre outros fatores, da presença de nichos ecológicos, como anfractuosidades dentais (Loesche et al., 1984; Badet e Thebaud, 2008), molares parcialmente irrompidos e acessórios ortodônticos (Sakamaki e Bahn, 1968; Meurman et al., 1987; Lundstrom e Krasse, 1987; Botha, 1993; Chang et al., 1999), os quais favorecem a retenção e o desenvolvimento desses microrganismos (Meurman et al., 1987; Tanzer et al., 2001).

Uma forte correlação tem sido estabelecida entre os níveis de Lactobacillus e o desenvolvimento de lesões de cárie (Badet e Thebaud, 2008), em função da produção de ácidos, que reduzem o pH do meio (Rosen et al., 1968) e por apresentarem a capacidade de sobreviver em ambientes com pH 
ácido (Badet et al., 2001), à semelhança do que ocorre com os $S$. mutans e $S$. sobrinus.

Em Ortodontia, diversos autores também têm se preocupado em avaliar a contaminação microbiana da superfície de componentes específicos de aparelhos ortodônticos fixos e removíveis por $S$. mutans, $S$. sobrinus e Lactobacillus (Anhoury et al., 2002; Steinberg e Eyal, 2004; Faltermeier et al., 2008) empregando particularmente técnicas de cultura microbiana (Ahn et al., 2003; Steinberg Eyal, 2004; Ahn et al., 2005; Leung et al., 2006; Papaioannou et al., 2007; Brusca et al., 2007; Lessa et al., 2007; Ahn et al., 2007; Lim et al., 2008; Magno et al., 2008).

No entanto, com o advento das novas técnicas de biologia molecular, avanços ocorreram na área da Microbiologia, tornando possível a identificação de espécies bacterianas de maneira mais confiável, por meio de sondas de DNA. Dentre as técnicas de biologia molecular destaca-se a técnica Checkerboard DNA-DNA Hybridization, empregada em Odontologia nas áreas de Periodontia (Teles et al., 2007; Matarazzo et al., 2008; Ioannou et al., 2009), Endodontia (Vianna et al., 2008; Siqueira e Rôças, 2009), Implantodontia (Nascimento et al., 2009), Odontopediatria (Ruviere et al., 2007; Youravong et al., 2007; Gizani et al., 2008) e Cariologia (Filoche et al., 2008; Haffajee et al., 2008), entre outras.

A técnica Checkerboard DNA-DNA Hybridization foi preconizada por Sockransky et al., em 1994. Este método de diagnóstico oferece vantagens em relação aos métodos tradicionais de cultura microbiana, incluindo a detecção de microrganismos de desenvolvimento lento, nutricionalmente exigentes ou fastidiosos, além da detecção da microbiota não cultivável. Também, é um método preciso e mais rápido que o empregado na técnica PCR, pois utiliza várias sondas de DNA de uma única vez, podendo as amostras ser estocadas por longos períodos (Siqueira et al., 2000; Moraes et al., 2002).

Estudos empregando a técnica PCR foram efetuados, em Ortodontia, para analisar a contaminação por $S$. mutans no biofilme ao redor de bráquetes após colagem ortodôntica (Ai et al., 2005) e a contaminação bacteriana em bráquetes (Ahn et al., 2007). No entanto, a técnica 
Checkerboard DNA-DNA Hybridization foi empregada em apenas um estudo piloto efetuado por Anhoury et al. (2002), para avaliar a contaminação em bráquetes metálicos e cerâmicos, após períodos de permanência na cavidade bucal não padronizados.

Para a prevenção e controle da instalação de processos patológicos na cavidade bucal, embora os métodos de higiene bucal nos pacientes portadores de aparelhos ortodônticos devam ser enfatizados (Naranjo et al., 2006; Lim et al., 2008), em crianças, jovens e idosos a destreza manual e o cuidado com a higiene bucal, na maior parte das vezes, são fatores que comprometem o controle mecânico do biofilme (Dills et al., 1988). Adicionalmente, segundo Smiech-Slombowska e Jablonska-Zrobek (2007), embora a escovação e o uso do fio dental sejam de fundamental importância, essas medidas não reduzem os níveis salivares de $S$. mutans e de Lactobacillus em pacientes portadores de aparelhos ortodônticos.

Pelo exposto, vários autores têm preconizado diferentes protocolos de uso de agentes antimicrobianos, particularmente a clorexidina, principalmente sob a forma de bochechos, sprays ou vernizes, como coadjuvantes no controle do biofilme dental e do biofilme dos aparelhos ortodônticos (Fardal e Turnbull, 1986; Brightman et al., 1991; Lessa et al., 2007; Sari e Birinci, 2007; Peixoto, 2007; Bagatin-Rossi, 2007; Maruo et al., 2008; Alves et al., 2008; Derks et al., 2008). Um enfoque especial tem sido dado à clorexidina, pois esta é considerada o antimicrobiano "padrão ouro", quando comparada aos demais agentes disponíveis no comércio especializado (Moshrefi, 2002).

No entanto, até o momento não há estudos publicados avaliando a detecção de microrganismos cariogênicos em bráquetes ortodônticos metálicos, com e sem o uso de agentes antimicrobianos, empregando técnicas de biologia molecular como o Checkerboard DNA-DNA Hybridization. 
2 Proposição

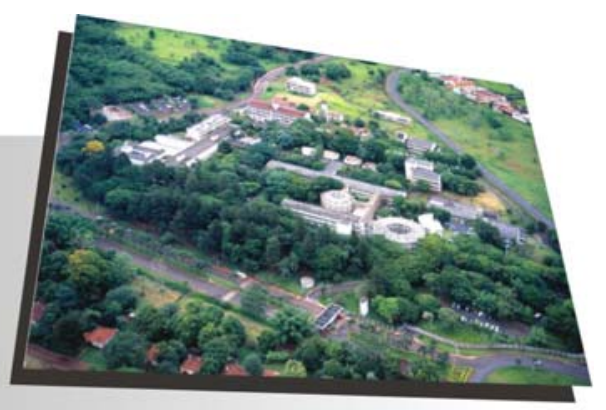




\section{Proposi Ção}

O objetivo do presente estudo clínico randomizado foi avaliar in vivo, por meio da técnica de biologia molecular Checkerboard DNA-DNA Hybridization:

- A contaminação de bráquetes metálicos por 4 espécies bacterianas de microrganismos cariogênicos (Streptococcus mutans, Streptococcus sobrinus, Lactobacillus casei e Lactobacillus acidophilus), 30 dias após sua colocação na cavidade bucal; e

- A eficácia da utilização do gluconato de clorexidina a 0,12\% (Periogard $^{\circledR}$ ) sobre esses microrganismos, sob a forma de bochecho, duas vezes por semana, durante 30 dias. 
3 Material e Método

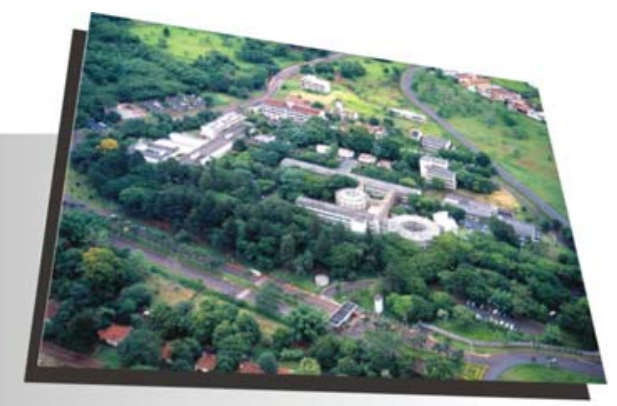




\section{Materi al e Método}

\section{Seleção da amostra}

Após a aprovação do projeto pelo Comitê de Ética em Pesquisa envolvendo Seres Humanos, da Faculdade de Odontologia de Ribeirão Preto da Universidade de São Paulo (processo $\mathrm{n}^{\circ}$ 2008.1.163.58.8), foi obtido 0 consentimento livre e esclarecido dos pacientes (ou responsáveis) que fizeram parte da pesquisa. Foram selecionados 39 pacientes de 11 a 33 anos de idade, de ambos os gêneros, com dentição permanente completa, em tratamento com aparelho ortodôntico fixono Curso de Especialização em Ortodontia do Departamento de Clínica Infantil, Odontologia Preventiva e Social - Faculdade de Odontologia de Ribeirão Preto - Universidade de São Paulo, por um tempo máximo de 1 ano.

Esses indivíduos não poderiam ter feito uso de antibióticos e/ou bochechos com soluções antimicrobianas por um período mínimo de 3 meses, previamente ao início da pesquisa. Além disso, deveriam apresentar boa saúde geral, verificada por meio de anamnese detalhada, não devendo apresentar, no momento da realização da pesquisa, alterações sistêmicas significativas que pudessem interferir na realização do estudo.

\section{Instalação dos aparelhos e divisão dos grupos (randomização)}

Uma semana antes do início do experimento foi efetuada a avaliação do índice de placa (biofilme dental) (Silness e Loe, 1964) por um único operador,seguida de rigorosa profilaxia com pedra-pomes e água após evidenciação do biofilme dental com solução de fuccina básica (Replak, Dentsply, Catanduva, SP, Brazil). Os pacientes receberam, então, instruções de higiene bucal individualmente, sendo orientados a escovar os dentes 3 vezes ao dia. Em seguida, cada paciente recebeu uma escova dental Professional ${ }^{\circledR}$ (Colgate-Palmolive Indústria e Comércio Ltda, SP, Brazil) e dentifrício fluoretado Colgate Máxima Proteção Anticáries ${ }^{\circledast}$ (Colgate-Palmolive Indústria e Comércio Ltda, SP, Brazil), para realizar a higienização diária durante o período do experimento. 
Os 39 pacientes selecionados foram aleatoriamente divididos em dois grupos (Controle e Experimental) com o auxílio do programa SAS (Statistical Analysis System) for Windows versão 9.1.3 (SAS Institute Inc, Cary, NC, USA), de acordo com o gênero. Posteriormente, foi efetuada nova aleatorização dentro de cada grupo, para determinar quais dentes seriam utilizados (15 e 25 / 35 e 45). Cada paciente selecionado recebeu novos bráquetes metálicos com slot 0.022"X0.028" e prescrição Edgewise (Generus; GAC International Inc, Bohemia, NY), previamente autoclavados, em 2 prémolares previamente determinados, colados com adesivo ortodôntico fotopolimerizável em seringas (Sistema Transbond XT; 3M Unitek, Monrovia, Calif), seguindo as instruções do fabricante.

Os pacientes do Grupo Controle $(n=20)$ foram orientados a fazer bochechos com solução placebo manipulada (Farmácia de manipulação Doce Erva - RP - Brazil) com cor, sabor e composição semelhantes ao Periogard $^{\circledR}$ (glicerina $10 \%$, polissorbarto $0,5 \%$, essência de menta $0,05 \%$, sacarina 0,05\%, corante azul 1 x 0,25\% e água destilada QSP $1000 \mathrm{~mL}$ ), porém sem adição de clorexidina em sua composição. Foram efetuados 2 bochechos semanais com $10 \mathrm{~mL}$ da solução, por 30 segundos, durante 30 dias. Um dos bochechos foi realizado na clínica da Faculdade de Odontologia de Ribeirão Preto - USP, sob supervisão profissional, enquanto que o outro bochecho foi realizado à noite, no domicílio, no mínimo 1 hora após a escovação dental, como sugerido por Bagatin-Rossi (2007).

Os pacientes do Grupo Experimental $(n=19)$ foram orientados a fazer bochechos com solução antimicrobiana à base de gluconato de clorexidina a 0,12\% (Periogard ${ }^{\circledR}$ - Colgate-Palmolive Indústria e Comércio Ltda, SP, Brazil), da mesma forma anteriormente descrita para o grupo Controle. Ambas as soluções foram acondicionadas em frascos plásticos de $120 \mathrm{~mL}$ e fornecidas aos pacientes no momento da recolagem dos bráquetes, na semana seguinte à profilaxia. Os pacientes não tiveram conhecimento de qual das 2 soluções (placebo ou com clorexidina) estavam utilizando nos bochechos.

Decorridos 30 dias, os 2 bráquetes foram removidos de cada paciente, de ambos os grupos, com alicate ortodôntico (How reto - TP Orthodontics- USA) e processados para posterior análise. Todos os 
procedimentos clínicos foram realizados por um único operador (cirurgiãodentista).

\section{Processamento das amostras dos bráquetes}

Cada bráquete, com e sem uso de solução antimicrobiana, foi colocado individualmente em tubos plásticos para microcentrífuga (Eppendorf AG Barkhausenweg 122339 - Hamburg, Germany), contendo $150 \mu \mathrm{L}$ de solução tampão TE (pH 7,6) e $100 \mu \mathrm{L}$ de $\mathrm{NaOH}$ a 0,5 M, codificados e agitados vigorosamente em aparelho Mixtron (Toptronix - São Paulo - SP), em velocidade máxima, durante 30 segundos, para dessorção do material. Os bráquetes foram então removidos com uma pinça clínica esterilizada e os tubos contendo a suspensão bacteriana foram estocados a $-20^{\circ} \mathrm{C}$ para que as amostras fossem submetidas oportunamente à técnica Checkerboard DNA-DNA Hybridization.

\section{Cepas bacterianas e condições de crescimento}

O processamento/análise das amostras foi realizado no Laboratório de Pesquisa em Odontologia II, Microbiologia, Imunologia e Biologia Molecular da Universidade de Guarulhos.

A relação das 4 cepas bacterianas de microrganismos relacionados com a etiologia da cárie dental, utilizadas neste estudo para o preparo das sondas de DNA, está apresentada na Tabela 1. As cepas de Streptococcus mutans, Streptococcus sobrinus, Lactobacillus casei e Lactobacillus acidophilus foram adquiridas liofilizadas da ATCC (Americam Type Culture Collection, Rockville, MD, EUA). O conteúdo liofilizado foi reidratado em caldo para crescimento de Mycoplasma (Difco Laboratories, Detroit, MI, EUA) e cultivado em ágar-triptose de soja (Difco) contendo $5 \%$ de sangue desfibrinado de ovelha (BBL, Baltimore Biological Laboratories, Cockeysville, MD, EUA) a 35ㄷ sob condição de anaerobiose $\left(80 \% \mathrm{~N}_{2}, 10 \% \mathrm{CO}_{2}, 10 \% \mathrm{H}_{2}\right)$. 
Tabela 1-Relação das cepas bacterianas empregadas para a confecção das sondas de DNA

\begin{tabular}{ll}
\hline Espécies & Cepas \\
\hline Streptococcusmutans & ATCC 25175 \\
Streptococcussobrinus & ATCC 33748 \\
Lactobacillus acidophillus & ATCC 4356 \\
Lactobacillus casei & ATCC 393
\end{tabular}

ATCC: American Type Culture Collection

\section{Isolamento do DNA e preparo das sondas}

As cepas bacterianas foram cultivadas anaerobicamente na superfície do meio ágar-sangue, por 3 a 7 dias. As colônias foram raspadas e depositadas em tubos plásticos para microcentrífuga de $1,5 \mathrm{~mL}$ contendo $1 \mathrm{~mL}$ de solução TE $(\mathrm{pH} 7,6)$. As células foram lavadas 2 vezes por centrifugação na solução-tampão de TE a 3.500xg por 10 minutos. Em seguida, as cepas bacterianas foram lisadas em $150 \mu \mathrm{L}$ de uma mistura enzimática contendo 15 $\mathrm{mg} / \mathrm{mL}$ de lisozima (Sigma) e $5 \mathrm{mg} / \mathrm{mL}$ de acromopeptidase (Sigma) em solução tampão TE ( $\mathrm{pH}$ 8,0). O DNA foi isolado e purificado como descrito por Smith et al.(1989). As sondas genômicas foram preparadas para cada uma das 4 espécies pela marcação de $1 \mu \mathrm{g}$ do DNA bacteriano com digoxigenina, por meio do Random primer digoxigenin labeling kit (Roche Diagnostics, Indianápolis, IN, EUA), de acordo com o método descrito por Feinberg e Vogelstein (1983).

\section{Checkerboard DNA-DNA Hybridization}

As suspensões contidas nos tubos plásticos foram fervidas em banho-maria por 10 minutos e, em seguida, neutralizadas pela adição de 800 $\mu \mathrm{L}$ de acetato de amônia a $5 \mathrm{M}$. Cada suspensão contendo o DNA livre das bactérias presentes nas amostras dos bráquetes foi depositada em uma das canaletas do aparelho Minislot 30 (Immunetics, Cambridge, MA, EUA - Figura 1) e transferida para a membrana de nylon $(15 \times 15 \mathrm{~cm})$ com carga positiva (Amersham Biosciences UK Limited, Buckinghamshire, Inglaterra). As duas últimas das 30 canaletas do Minislot foram ocupadas por controles contendo uma mistura das espécies de microrganismos investigados pelas sondas, nas 
concentrações correspondentes a $10^{5}$ e $10^{6}$ células, ou seja, 1 ng e 10 ng de DNA de cada espécie, respectivamente. A membrana foi então removida do Minislot 30 e o DNA nela concentrado foi fixado por aquecimento em forno a $120^{\circ} \mathrm{C}$ por 20 minutos.

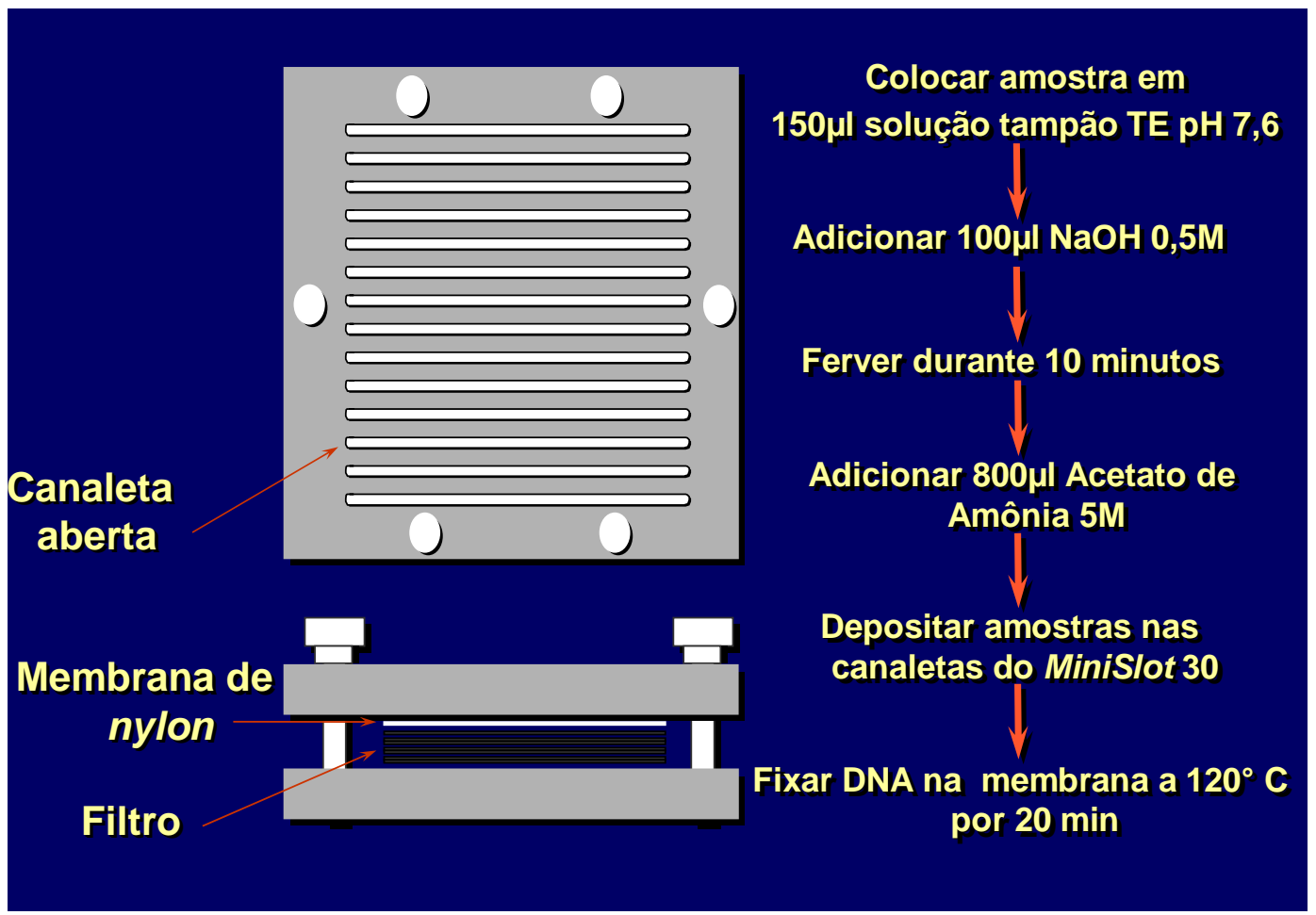

Figura1-Representação esquemática do Minislot 30 (I mmunetics, Cambridge, MA, EUA) e resumo da preparação e colocação das amostras na membrana de nylon (técnica checkerboard DNA-DNA hybridization).

A membrana foi pré-hibridizada a $42^{\circ} \mathrm{C}$, por 1 hora, em uma solução contendo 50\% de formamida (Vetec Química Fina Ltda, Rio de Janeiro, RJ, Brasil), 1\% de caseína (Vetec), 5 x solução salina citratada (SSC) [1 x SSC= $150 \mathrm{mM} \mathrm{NaCl}$ (Vetec), 15 M de citrato de sódio (J.T. Baker, Edo. de Méx., México) , pH 7,0], 25 mM de fosfato de sódio $\left(\mathrm{Na}_{2} \mathrm{HPO}_{4}\right.$, Labsynth) $\mathrm{pH}$ 6,5 e 0,5 $\mathrm{mg} / \mathrm{mL}$ de RNA de levedura (Sigma).

Em seguida a membrana foi posicionada no Miniblotter 45 (Immunetics, Cambridge, MA, EUA - Figura 2) com as linhas contendo o DNA das amostras e dos controles posicionadas perpendicularmente às canaletas do aparato. Em cada canaleta do Miniblotter 45 foiadicionada uma sonda de DNA, diluída a aproximadamente 20 ng/mL, em $130 \mu \mathrm{L}$ de solução de hibridização 


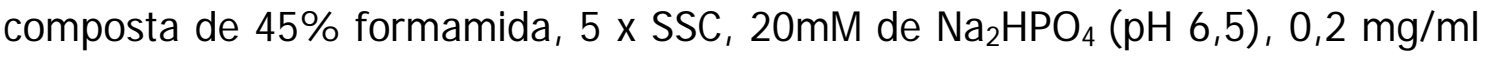
de RNA de levedura, 10\% de sulfato de dextrano (Amersham) e 1\% de caseína. Para a hibridização, aguardou-se um período mínimo de 20 horas, a $42^{\circ} \mathrm{C}$.

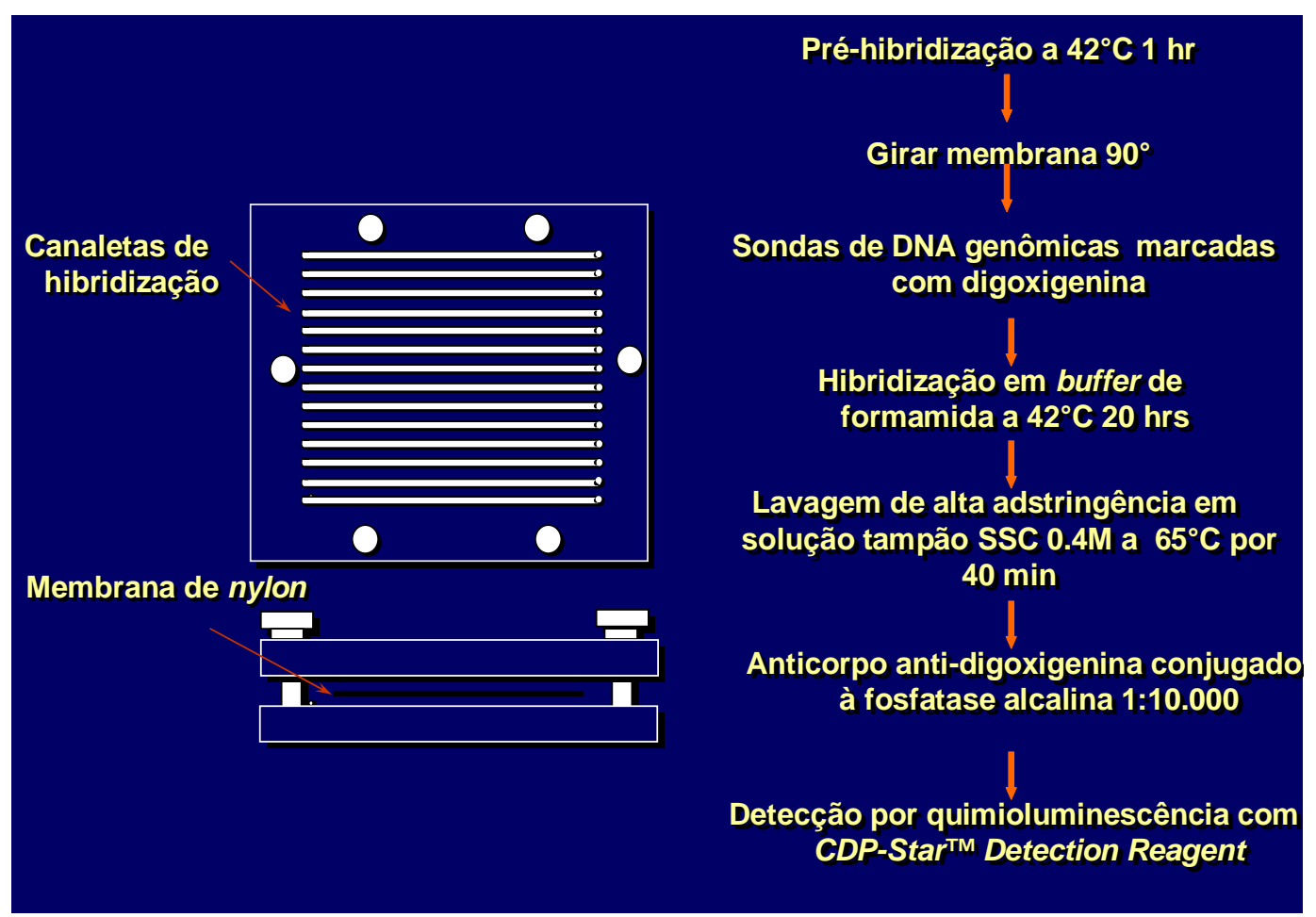

Figura 2-Representação esquemática do Miniblotter 45 (Immunetics, Cambridge, MA, EUA) e resumo das etapas de hibridização e detecção das espécies bacterianas presentes nas amostras (técnica checkerboard DNA-DNA hybridization).

\section{Detecção das espécies}

Após o período de hibridização, a membrana foi removida do Miniblotter 45 (Immunetics), lavada por 40 minutos a $65^{\circ} \mathrm{C}$ numa solução adstringente (solução tampão SSC a 0,4 M) composta por 1\% de SDS, 1 mM de EDTA e $20 \mathrm{mM}$ de $\mathrm{Na}_{2} \mathrm{HPO}_{4}$, a fim de remover sondas que não hibridizaram completamente. Em seguida, a membrana foi imersa por 1 hora em uma solução contendo $1 \%$ de ácido maléico $\left(\mathrm{C}_{4} \mathrm{H}_{4} \mathrm{O}_{4}\right.$, Vetec), $3 \mathrm{M} \mathrm{NaCl}, 0,2 \mathrm{M} \mathrm{NaOH}$ (Labsynth), 0,3\% Tween 20 (Vetec), 0,5\% caseína, pH 8,0, e, logo após, por 30 minutos, na mesma solução contendo o anticorpo anti-digoxigenina conjugado à fosfatase alcalina (Roche) em uma concentração de 1:10.000. A membrana foi, então, lavada 2 vezes, por 20 minutos, em uma solução de 0,1 $\mathrm{M}$ de ácido maléico, $3 \mathrm{M}$ de $\mathrm{NaCL}, 0,2 \mathrm{M}$ de $\mathrm{NaOH}, 0,3 \%$ de Tween 20, $\mathrm{pH}$ 8,0, 
e 1 vez, por 5 minutos, em uma solução de 0,1 $\mathrm{M}$ de $\mathrm{TrisHCl}$ e 0,1 M de $\mathrm{NaCl}$, $\mathrm{pH} \mathrm{9,5.}$

Para a detecção dos sinais de quimioluminiscência a membrana foi incubada por 45 minutos a $37^{\circ} \mathrm{C}$ em uma solução detectora contendo substrato para fosfatase alcalina, CDP-Star ${ }^{T M}$ Detection Reagent (Amersham). Em seguida, a membrana foi colocada em um cassete de autoradiografia, Chassi Radiográfico $30 \times 40 \mathrm{~cm}$ (Konex, São Paulo, SP, Brasil), sob um filme radiográfico $18 \times 24 \mathrm{~cm}$ (Agfa Gevaert, NV, Bélgica) por, aproximadamente, 40 minutos. O filme foi reveladomanualmente pelo método convencional tempotemperatura, de acordo com orientações do fabricante, empregando soluções Kodak (Kodak Brasileira Com. e Ind. Ltda, São José dos Campos, SP, Brasil), mantidas à temperatura de $20^{\circ} \mathrm{C}$.

Desta forma, foi obtido um filme radiográfico com os sinais de quimioluminiscência detectados pelas sondas de DNA, onde as linhas horizontais representam as amostras e as verticais as sondas de DNA, propiciando um formato de "tabuleiro de xadrez" (Figura 3).

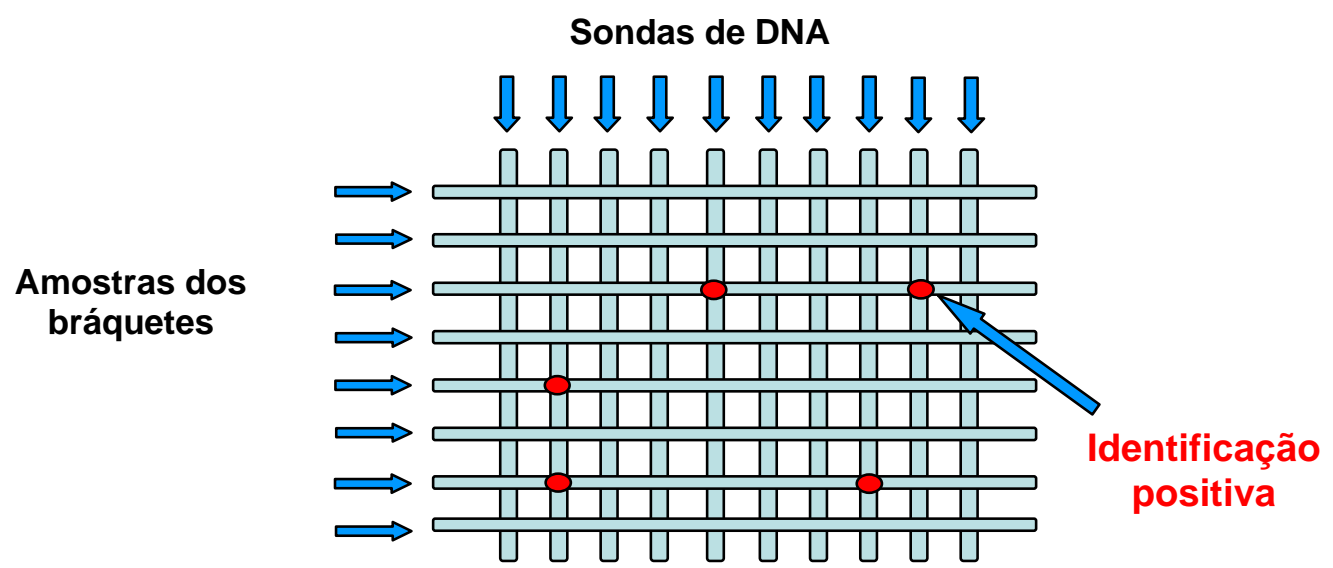

Figura 3- Representação esquemática do padrão de hibridização entre as bactérias presentes nas amostras e as sondas de DNA (técnica checkerboard DNA-DNA hybridization).

A leitura dos filmes radiográficos foi realizada por um único examinador calibrado (Kappa>0,8) e cego com relação aos grupos avaliados. A leitura foi realizada 2 vezes, em dias diferentes, para conferência dos resultados. Quando as leituras não foram coincidentes, foi realizada uma terceira leitura dos resultados para aquela amostra. A intensidade de cada sinal 
produzido por uma determinada sonda na suspensão microbiana oriunda dos bráquetes foi comparada ao sinal produzido pela mesma sonda nas 2 linhas de controles contendo $10^{5}$ e $10^{6}$ bactérias.

A fim de facilitar a anotação dos resultados em fichas específicas, com relação aos microrganismos avaliados ( $S$. mutans, $S$. sobrinus, $L$. acidophilus e $L$. casel) foram empregados os seguintes escores:

- Escore 0: registrado quando não houve detecção de sinal de quimioluminiscência;

- Escore 1: quando observou-se um sinal menos intenso que o controle de $10^{5}$ células;

- Escore 2: sinal equivalente a $10^{5}$ células;

- Escore 3: sinal entre $10^{5}$ e $10^{6}$ células;

- Escore 4: sinal equivalente a $10^{6}$ células; e

- Escore 5 : sinal equivalente a mais de $10^{6}$ células.

A análise estatística foi efetuada convertendo-se os escores em valores numéricos originais (Tabela 2). Tendo em vista que foram removidos 2 bráquetes de cada paciente, foi efetuada a média dos 2 valores obtidos. Estes registros foram utilizados para determinar os níveis das diferentes espécies investigadas nas diferentes amostras.

Tabela 2- Conversão dos escores em valores numéricos originais, para cada microrganismo avaliado nas suspensões microbianas oriundas de bráquetes metálicos, in vivo, pela técnica Checkerboard DNA-DNA Hybridization

\begin{tabular}{ccc}
\hline Escore & Nível de detecção do microrganismo & $\begin{array}{c}\text { Número de } \\
\text { microrganismos }\end{array}$ \\
\hline 0 & Não detectado & 0 \\
1 & Menos de $10^{5}$ células & $10.000\left(1 \times 10^{4}\right)$ \\
2 & Aproximadamente $10^{5}$ células & $100.000\left(1 \times 10^{5}\right)$ \\
3 & Entre $10^{5}$ e $10^{6}$ células & $500.000\left(5 \times 10^{5}\right)$ \\
4 & Aproximadamente $10^{6}$ células & $1.000 .000\left(1 \times 10^{6}\right)$ \\
5 & Mais de $10^{6}$ células & $10.000 .000\left(1 \times 10^{7}\right)$ \\
\hline
\end{tabular}




\section{Análise Estatística}

A fim de verificar se a aleatorização dos indivíduos nos grupos Controle e Experimental foi adequada, os grupos foram comparados com relação à distribuição da idade, do gênero e da quantidade de biofilme dental. Com essa finalidade, foram empregados os testes de qui-quadrado (para comparação da proporção dos gêneros), teste t (para comparação das médias das idades) e Kruskal-Wallis (para distribuição não-paramétricada quantidade de biofilme dental).

Os resultados obtidos com a técnica Checkerboard DNA-DNA Hybridization foram analisados por meio do teste não-paramétrico de KruskalWallis, utilizando o software SAS (Statistical Analysis System) for Windows versão 9.1.3 (SAS Institute Inc. Cary, NC, USA). A fim de avaliar o nível de contaminação dos bráquetes por cada um dos 4 microrganismos avaliados, assim como a eficácia do uso de bochechos com gluconato de clorexidina a $0,12 \%$, a quantidade detectada de células das diferentes espécies bacterianas foi comparada nos bráquetes dos grupos Controle e Experimental.

0 nível de significância adotado foi de 5\% . 
4 Resultados

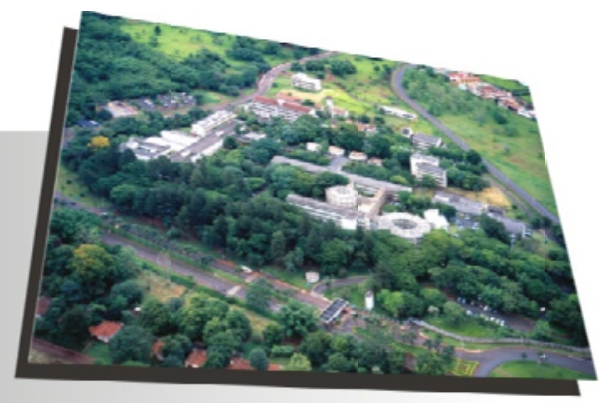




\section{Resultados}

Os 39 pacientes (100\%) selecionados para o estudo participaram do mesmo até a sua conclusão.

Os resultados da análise da aleatorização dos indivíduos nos grupos Controle e Experimental encontra-se na tabela 3. Verificou-se que não houve diferença estatisticamente significante entre os indivíduos dos 2 grupos, com relação ao gênero e à quantidade de biofilme dental $(p>0,05)$. No entanto, com relação à idade, observou-se maiores valores de mediana para o grupo Experimental $(p=0,02)$.

Tabela 3 - Caracterização comparativa dos indivíduos dos grupos Controle (uso de bochechos com solução placebo) e Experimental (uso de bochechos com gluconato de clorexidina a 0,12\%)

\begin{tabular}{|c|c|c|c|}
\hline Variável & Grupo Controle & Grupo Experimental & $p$ \\
\hline I dade & $13(12-16)$ & $17(13-24)$ & $p=0,02^{*}$ \\
\hline \multirow[t]{2}{*}{ Gênero } & Masculino: 57,9\% & Masculino: $42,9 \%$ & $p=0,34^{* *}$ \\
\hline & Feminino: $40,1 \%$ & Feminino: $57,1 \%$ & \\
\hline $\begin{array}{l}\text { Quantidade de } \\
\text { biofilme dental }^{\dagger}\end{array}$ & $1,8(1,1-2,0)$ & $1,4(1,0-2,0)$ & $p=0,75^{* * *}$ \\
\hline $\begin{array}{l}\text { s valores referentes à } \\
\text { nediana, } \mathrm{Q} 1=\text { primeiro } \mathrm{q} \\
\text { : Quantidade de biofilme } \\
\text { : valor de } \mathrm{p} \text { para o teste } \\
* \text { : valor de p para o test } \\
\text { * }^{* *} \text { valor de p para o test }\end{array}$ & $\begin{array}{l}\text { à quantidade de biofi } \\
\text { e Q3= terceiro quartil } \\
\text { l obtida por meio da ave } \\
\text { uadrado } \\
\text { ruskal-Wallis. }\end{array}$ & $\begin{array}{l}\text { tal encontram-se expressos } \\
\text { o índice de placa (Silness e L }\end{array}$ & $\begin{array}{l}\text { M(Q1-Q3), } \\
964)\end{array}$ \\
\hline
\end{tabular}

\section{Grupo Controle}

(Uso de bochechos com solução placebo)

Os microrganismos avaliados (S. mutans, S. sobrinus, L. casei e $L$. acidophilus) foram detectados em $100 \%$ das amostras dos bráquetes desse grupo. 
No entanto, quando comparou-se, numericamente, os níveis de detecção desses microrganismos nas amostras (número de células bacterianas/bráquete), observou-se que essas encontravam-se mais densamente contaminadas por $S$. mutans e $S$. sobrinus, sem diferença entre eles $(p=0,58)$, seguidos pelos $L$. casei e $L$. acidophilus $(p<0,01)$.

\section{Grupo Experimental}

(Uso de bochechos com gluconato de clorexidina a 0,12\%)

À semelhança do que ocorreu no grupo Controle, todos os microrganismos testados (S. mutans, S. sobrinus, L. casei e L. acidophilus) foram detectados no grupo Experimental, em todas as amostras oriundas dos bráquetes ortodônticos (100\% de detecção).

Embora as quantidades de $S$. mutans, S. sobrinus, L. casei e $L$. acidophilus tenham sofrido redução numérica após o uso dos bochechos com solução de gluconato de clorexidina a $0,12 \%$, a comparação com os valores observados no grupo Controle evidenciou diferença estatisticamente significante apenas para $S$. mutans $(\mathrm{p}=0,03)$.

As Figuras4 e 5 apresentam os resultados das contagens dos diferentes microrganismos avaliados, em porcentagem do número médio de células bacterianas, nos grupos Controle e Experimental. 


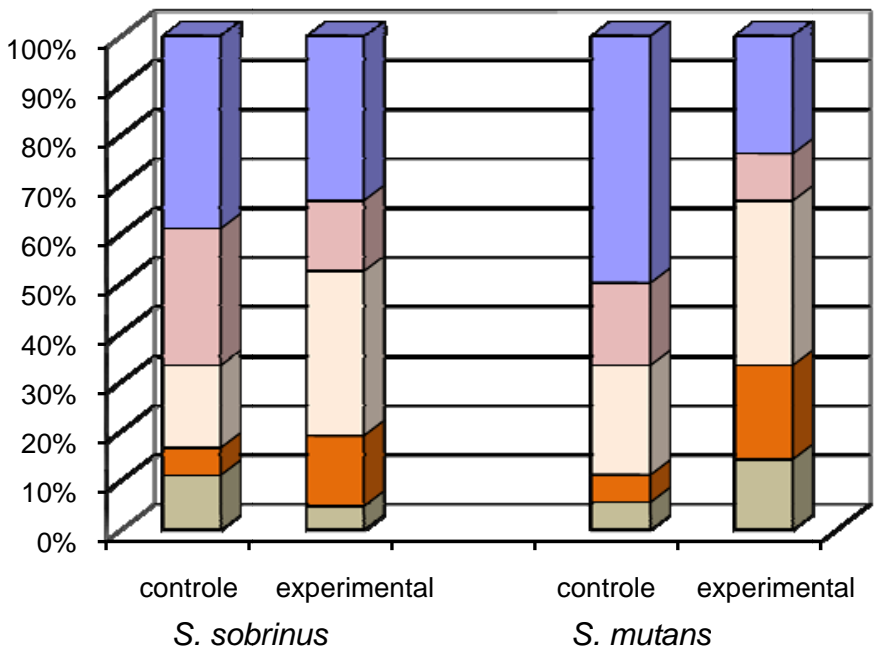

$\square 5 \times 10^{5}$

口3 $\times 10^{5}$

$\square 1 \times 10^{5}$

$\square 5 \times 10^{4}$

$\square 10^{4}$

Figura 4 - Porcentagem do número médio de células de $S$. mutans e $S$. sobrinus detectadas nas amostras oriundas dos bráquetes ortodônticos dos grupos Controle (uso de bochechos com solução placebo) e Experimental (uso de bochechos com solução de gluconato de clorexidina a $0,12 \%$ ).

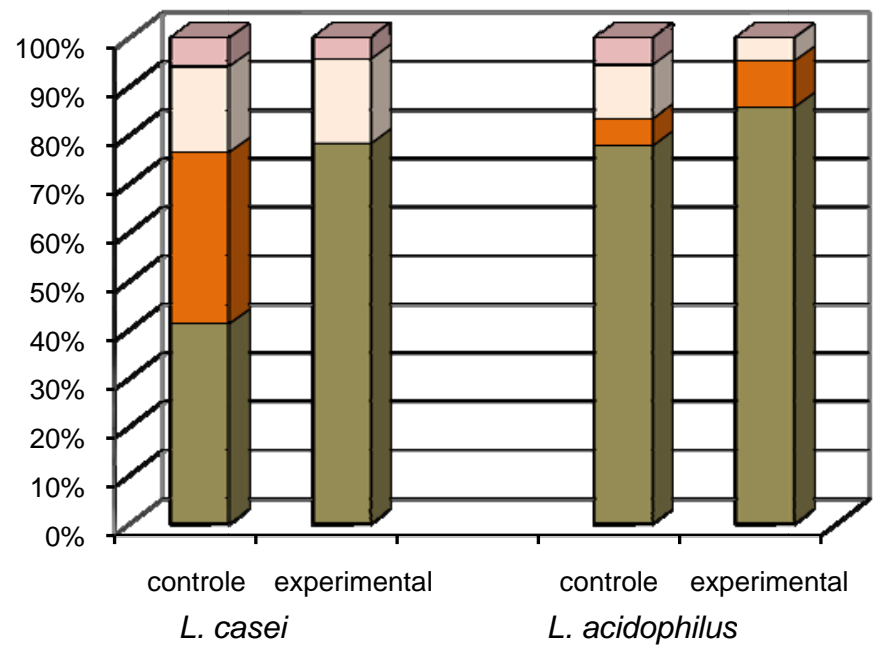

$\square 3 \times 10^{5}$

ㅁ1 $\times 10^{5}$

प4 $\times 10^{4}$

$\square 1 \times 10^{4}$

Figura 5 - Porcentagem do número médio de células de $L$. casei e $L$. acidophilus detectadas nas amostras oriundas dos bráquetes ortodônticos dos grupos Controle (uso de bochechos com solução placebo) e Experimental (uso de bochechos com solução de gluconato de clorexidina a $0,12 \%$ ). 
0 resultado das comparações entre os 2 grupos pode ser evidenciado na Tabela 4.

Tabela 4 - Resultados das comparações entre os grupos Controle (uso de bochechos com solução placebo) e Experimental (uso de bochechos com gluconato de clorexidina a 0,12\%), com relação aos diferentes microrganismos avaliados

\begin{tabular}{lccc}
\hline Microrganismo & Grupo Controle & Grupo Experimental & $\boldsymbol{p}^{*}$ \\
\cline { 2 - 3 } S. mutans & $\mathrm{M}(\mathrm{Q} 1-\mathrm{Q} 3)$ & $\mathrm{M}(\mathrm{Q} 1-\mathrm{Q} 3)$ & \\
& 400.000 & 100.000 & 0,03 \\
& $(100.000-500.000)$ & $(55.000-300.000)$ & \\
S. sobrinus & 300.000 & & \multirow{2}{*}{0,54} \\
& $(5.000-500.000)$ & $(5.000-500.000)$ & \\
L. casei & 50.000 & 100.000 & 0,18 \\
& $(10.000-55.000)$ & $(10.000-10.000)$ & \\
L. acidophilus & 10.000 & & 0,28 \\
& $(10.000-10.000)$ & $(10.000-10.000)$ & \\
\hline
\end{tabular}

": valor de p para o teste de Kruskal-Wallis

Os valores encontram-se expressos como $\mathrm{M}(\mathrm{Q} 1-\mathrm{Q} 3)$, onde $\mathrm{M}=$ mediana, $\mathrm{Q} 1=$ primeiro quartil e $\mathrm{Q} 3=$ terceiro quartil. 
5 DiscussÃo

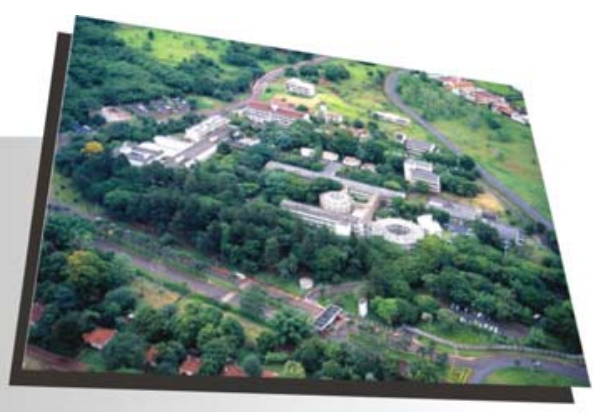




\section{Discussão}

\section{1) DA Metodologia}

o presente estudo foi clínico randomizado, cujo tipo de amostragem tem como objetivo minimizar a incorporação de vieses, os quais poderiam agir como fatores de confusão, interferindo nos resultados obtidos. Optou-se pela realização de um estudo clínico randomizado, pois esse representa o "padrão ouro" (delineamento ideal) das pesquisas que avaliam a eficácia clínica de materiais e técnicas de tratamento (Fletcher et al., 2002). Todos os elementos da população têm igual probabilidade de pertencer à amostra, e todas as possíveis amostras têm também igual probabilidade de ocorrer (Costa Neto, 2002).

De acordo com a análise estatística da aleatorização dos indivíduos que participaram dos grupos Controle e Experimental, observou-se que não houve diferença entre os 2 grupos, com relação ao gênero e à quantidade de biofilme dental inicial $(p>0,05)$. Por outro lado, observou-se maiores valores de mediana de idade no grupo Experimental $(p=0,02)$. No entanto, embora a idade dos pacientes tenha sido maior nos indivíduos do grupo Experimental, a quantidade de biofilme dental inicialmente foi semelhante nos 2 grupos $(p=0,75)$. Ainda, pôde-se verificar que embora os indivíduos do grupo Experimental tivessem mais idade, esse fato provavelmente não influenciou nos resultados obtidos, pois eliminando-se os indivíduos acima de 20 anos, a análise estatística evidenciou os mesmos resultados.

A fim de minimizar ainda mais os possíveis fatores de confusão que pudessem interferir nos resultados, após a colagem dos bráquetes, 0 material para higiene (escova e dentifrício padronizados) e desinfecção (frascos plásticos com solução placebo ou experimental) foi entregue aos indivíduos participantes do estudo, que receberam as orientações com relação à maneira e freqüência da escovação e de uso dos bochechos, de acordo com cada grupo, efetuada por um mesmo profissional cirurgião-dentista. Salienta-se que os 
indivíduos não tinham conhecimento de qual solução (placebo ou com clorexidina) estavam utilizando para os bochechos.

Apesar desses cuidados acreditamos que, assim como em qualquer pesquisa clínica, alguns fatores inerentes à colaboração e dedicação por parte dos indivíduos que participaram do estudo possam ter apresentado alguma influência nos resultados. Como relatado por Featherstone (2006), a eficácia do uso domiciliar da clorexidina pode ter seu potencial subestimado, tendo em vista a necessidade da colaboração do paciente, para obter 0 resultado esperado.

A escolha da técnica Checkerboard DND-DNA Hybridization como método para a detecção de diferentes microrganismos em bráquetes ortodônticos in vivo se deu em função de que esse método oferece vantagens quando comparado à técnica PCR, uma vez que utiliza várias sondas de DNA de uma única vez possibilitando, assim, resultados mais rápidos e com custo relativamente menor. Outra vantagem é que as amostras podem ser avaliadas sem a necessidade de diluição ou amplificação, superando os problemas de quantificação impostos tanto pela diluição seriada quanto pelos procedimentos de amplificação da técnica PCR. Entretanto, a técnica Checkerboard DND-DNA Hybridization apresenta limitações peculiares, uma vez que detecta somente as espécies cujas sondas de DNA foram previamente selecionadas, sendo um método semi-quantitativo (Sockanskyet al., 2004).

A cavidade bucal apresenta inúmeras espécies de microrganismos presentes na saliva ou colonizando suas diferentes superfícies, sob a forma de biofilme (Fejerskov e Kidd, 2005). As 4 sondas de DNA utilizadas nesse estudo (S. mutans, S. sobrinus, L. casei e L. acidophilus) foram selecionadas devido ao seu importante papel na etiologia e desenvolvimento da cárie dental (Ajdic et al., 2002; Berkowitz, 2003; McNeill e Hamilton, 2003; Fejerskov e Kidd, 2005; Badet e Thebaud, 2008; Saito et al., 2009).

Os usuários de aparelhos ortodônticos apresentam níveis elevados de estreptococos do grupo mutans e lactobacilos na saliva e no biofilme dental (Mattingly et al., 1983; Anhoury et al., 2002; Jordan e Leblanc, 2002; Leung et al., 2006), detectados principalmente por meio do uso de técnicas de cultura 
microbiana e microscopia. Pacientes portadores de aparelhos ortodônticos também exibem maior tendência ao desenvolvimento de lesões de cárie, uma vez que esses proporcionam maior acúmulo de biofilme dental e, consequentemente, maiores níveis de estreptococos do grupo mutans (Bjerklin et al., 1983; Friedman et al., 1985; Amitha e Munshi, 1995; Batoni et al., 2001; Anhoury et al., 2002; Martins-Ortiz et al., 2004; Auschill et al., 2005; Sari e Birinci, 2007; Lessa et al., 2007; Magno et al., 2008) e de lactobacilos na cavidade bucal (Anhoury et al., 2002; Sari e Birinci, 2007).

A substância ideal para desinfecção de aparelhos ortodônticos deveria ser bactericida e possuir um amplo espectro de ação, ser atóxica, não carcinogênica e não irritante. Além disso, deveria ser de fácil uso, efetiva na remoção do biofilme sem provocar danos ao aparelho, quimicamente estável, não deveria conter álcool e deveria apresentar baixo custo (Kolstad e Petit, 1983).

Tendo em vista que não há um agente antimicrobiano que reúna todos os requisitos da substância ideal, concordamos com Moshrefi (2002) quando relatou que a clorexidina ainda é considerada o antimicrobiano "padrão ouro", quando comparada aos demais agentes utilizados para controle do biofilme dental. Assim, no presente estudo foi utilizado o Periogard ${ }^{\circledR}$ no grupo Experimental, sob a forma de bochechos, após a escovação do aparelho, que é uma solução à base de gluconato de clorexidina a $0,12 \%$, disponível no comércio e amplamente utilizada na prática odontológica, com finalidades diversas (Denton, 1991).

0 protocolo de uso (2 bochechos por semana) foi baseado nos estudos de Peixoto (2007) e de Bagatin-Rossi (2007) que observaram, por meio de cultura microbiana e microscopia eletrônica de varredura, a eficácia desse protocolo sobre estreptococos do grupo mutans, em aparelhos removíveis de acrílico e em disjuntores de Haas. 


\section{2) Dos Resultados do Grupo Controle}

(USO de BOCHECHOS COM SOluÇão PlaCebo)

Como já salientado, vários estudos têm evidenciado um aumento nos níveis de microrganismos cariogênicos na cavidade bucal, após a instalação de aparelhos ortodônticos (Mattingly et al., 1983; Anhoury et al., 2002; Jordan e Leblanc, 2002; Leung et al., 2006; Sari e Birinci, 2007; Lessa et al., 2007; Magno et al., 2008). Além disso, em função da aderência de Streptococcus mutans e de Streptococcus sobrinus à sua superfície (Steinberg e Eyal, 2004; Ahn et al., 2005; Brusca et al., 2007; Ahn et al., 2007; Papaioannou et al., 2007; Faltermier et al., 2008), os bráquetes ocasionam alterações específicas no meio ambiente bucal, como redução do pH e aumento do risco de cárie dental. No presente estudo, as 4 sondas cariogênicas empregadas (S. mutans, S. sobrinus, L. casei e L. acidophilus) foram detectadas em todos os pacientes (100\%) nos bráquetes do grupo Controle, evidenciando que essas espécies são componentes importantes da microbiota de indivíduos com aparelhos ortodônticos fixos.

Em humanos, os $S$. mutans são mais frequentemente isolados que os S. sobrinus (Loesche, 1986). No entanto, no presente estudo os $S$. sobrinus, assim como os $S$. mutans, estavam presentes em $100 \%$ dos pacientes do grupo Controle, em níveis elevados, sem diferença entre eles $(p=0,58)$. Sabe-se que os $S$. sobrinus são microrganismos altamente agressivos, uma vez que são mais acidogênicos que os S. mutans (De Soet et al., 1990), dominando o biofilme dentário em indivíduos que fazem uso irrestrito de sacarose. Por esse motivo, indivíduos que apresentam altas contagens de $S$. sobrinus na saliva ou no biofilme dental apresentam maior risco de cárie que indivíduos que apresentam apenas a espécie S. mutans (Kohler et al., 1988; Fujiwara et al., 1991; Hofling et al., 1999; Lindquist e Emilson, 2004).

A coexistência de $S$. sobrinus e $S$. mutans parece ser um importante fator no desenvolvimento da cárie dental (Lindquist e Emilson, 1991). Quando ambas as espécies estão presentes na cavidade bucal, evidencia-se maior experiência de cárie nos indivíduos que quando se detecta 
apenas S. mutans (Kohler e Bjarnason, 1987; Seki et al., 2006). No presente estudo, $100 \%$ dos pacientes do grupo Controle apresentaram-se multicolonizados, ou seja, apresentaram ambas as espécies, $S$. mutans e $S$. sobrinus. Segundo Rupf et al. (2006), a colonização por S. sobrinus representa um importante fator de risco adicional para a cárie dental.

Assim, no presente estudo o emprego da técnica de biologia molecular para a detecção de microrganismos cariogênicos in vivo evidenciou que pacientes sob tratamento ortodôntico corretivo, com o uso de bráquetes metálicos, apresentam maior risco de cárie, também por apresentarem-se multicolonizados por $S$. mutans e por $S$. sobrinus.

Com relação aos lactobacilos, Sari e Birinci, em 2007, efetuaram um estudo por meio de cultura microbiana. Observaram que após a instalação de aparelhos ortodônticos fixos com bráquetes os níveis de S. mutans foram de 460 unidades formadoras de colônia $(\log / \mathrm{mL})$, enquanto que os níveis de lactobacilos foram bem menores, na ordem de 34 unidades formadoras de colônia $(\log / \mathrm{mL})$. No presente estudo, empregando técnica de biologia molecular, também observou-se que a detecção de lactobacilos foi menor, ou seja, os bráquetes encontravam-se mais densamente contaminados por $S$. mutans e $S$. sobrinus, sem diferença entre eles $(p=0,58)$, seguidos pelos $L$. casei e $L$. acidophilus $(p<0,01)$.

Com a finalidade de avaliar a contaminação microbiana de bráquetes ortodônticos, o levantamento efetuado nas bases de dados permitiu verificar que, até 0 momento, apenas 3 estudos empregaram técnicas de biologia molecular para a detecção de microrganismos cariogênicos, sendo 2 deles com a técnica PCR e 1 com a técnica Checkerboard DNA-DNA Hybridization.

$\mathrm{Ai}$ et al. (2005) avaliaram a alteração na densidade de estreptococos do grupo mutans no biofilme dental, após colagem de bráquetes, em pacientes, pela técnica Real Time Fluorescence-Quantitative Polymerase Chain Reaction. Foram colhidas amostras de biofilme ao redor dos bráquetes antes e 4 semanas após a colagem dos mesmos. Observaram que a quantidade 
de estreptococos do grupo mutans aumentou significativamente após a colocação dos bráquetes.

Em 2007, Ahn et al. analisaram a prevalência de estreptococos do grupo mutans aderidos a bráquetes metálicos através do DNA das bactérias, extraído e amplificado por meio da Reação em Cadeia da Polimerase (PCR). Foram utilizados bráquetes dos incisivos superiores e inferiores de 80 pacientes, no momento da descolagem do aparelho. A prevalência de $S$. mutans foi aproximadamente duas vezes maior que a de $S$. sobrinus. No presente estudo, empregando a técnica Checkerboard DNA-DNA Hybridization observamos que, numericamente, os níveis de detecção de $S$. mutans também foram mais elevados que os de $S$. sobrinus, porém sem diferença estatisticamente significante $(p>0,05)$.

No entanto, a técnica Checkerboard DNA-DNA Hybridization foi empregada em apenas um estudo piloto efetuado por Anhoury et al. (2002). Esses autores compararam a contagem de microrganismos em 32 bráquetes metálicos e 16 cerâmicos no total, dois de cada paciente, obtidos da região de incisivo central e pré-molar superior no momento da descolagem do aparelho ao final do tratamento, após períodos não relatados de permanência na cavidade bucal. De acordo com os resultados obtidos, o tipo de bráquete não influenciou na contagem de microrganismos cariogênicos (Streptococcus mutans e Lactobacillus acidophilus). A contagem média para os bráquetes metálicos foi de $2,81 \times 10^{5} \pm 0,44$ para $S$. mutans e de $3,06 \times 10^{5} \pm 0,42$ para os $L$. acidophilus.

De acordo com nossos resultados, após um tempo padronizado (30 dias), os bráquetes encontraram-se mais densamente contaminadas por $S$. mutans e $S$. sobrinus, sem diferença entre eles $(p=0,58)$, seguidos pelos $L$. casei e L. acidophilus, enquanto que no estudo de Anhoury et al. (2002) essa contaminação foi numericamente um pouco maior para L. acidophilus que para S. mutans. Essa diferença pode ser possivelmente explicada pelo fato de que Anhoury et al. (2002) avaliaram bráquetes removidos no final do tratamento ortodôntico, ou seja, após longos períodos de permanência na cavidade bucal, o que pode ter aumentado a colonização posterior por lactobacilos. 


\section{3) DOS RESULTADOS DO GRUPO EXPERI MENTAL}

(USO DE BoCheChOS COM GluCONATO DE CLOREXIDINA A 0,12\%)

A clorexidina é uma biguanida (Hidalgo e Dominguez, 2001), descoberta na década de 40 por pesquisadores que buscavam desenvolver agentes antimalária (Parson, 1974). Embora nunca tenha sido utilizada no tratamento da malária, este agente antimicrobiano é amplamente utilizado na área médica, para o tratamento de queimaduras e anti-sepsia da pele, mãos e braços (Hidalgo e Dominguez, 2001), entre outras utilizações, desde 1950 (Lopes et al., 1992). A clorexidina tem sido empregada topicamente para o controle do biofilme dental desde 1959, porém foi a partir do estudo clássico de Loeet al., em 1976, que o seu uso se popularizou na Odontologia, particularmente em função do seu amplo espectro de ação, ou seja, sua eficácia contra microrganismos gram-positivos, gram-negativos, aeróbios, anaeróbios facultativos, leveduras e vírus (Hidalgo e Dominguez, 2001).

A atividade antimicrobiana da clorexidina origina-se de sua carga positiva em pH fisiológico, facilitando sua adesão de forma não específica à parede bacteriana, carregada negativamente. Esta interação ocasiona uma alteração no equilíbrio osmótico bacteriano, com extravasamento de potássio e fósforo e precipitação do citoplasma, com conseqüente morte da bactéria (Hidalgo e Dominguez, 2001). Adicionalmente, a adesão deste agente antimicrobiano à bactéria e às glicoproteínas salivares interfere na formação da película adquirida e na adsorção bacteriana ao dente (Rolla e Melsen, 1975).

A atividade antimicrobiana da clorexidina, in vivo, em parte é decorrente do seu efeito prolongado (substantividade), que é a propriedade de se adsorver, reversivelmente, à mucosa bucal, película adquirida, proteínas salivares e hidroxiapatita (Rolla et al., 1971), sendo lentamente liberada na cavidade bucal por até 24 horas (Gjermo et al., 1974). Quando utilizada topicamente, a clorexidina é uma substância segura, com baixo potencial de toxicidade (Loe et al., 1976; Fardal e Turnbull, 1986; Thylstrup e Fejerskov, 2001), não ocasionando alterações nas bactérias nem induzindo a seleção de cepas mutantes resistentes (Sreenivasan e Gaffar, 2002). 
Por outro lado, o uso prolongado da clorexidina pode ocasionar efeitos colaterais, como pigmentação marrom-amarelada da estrutura dental e restaurações, alterações na sensação gustativa (Fardal e Turnbull, 1986), sabor amargo e pigmentação do dorso da língua, entre outros (Fardal e Turnbull, 1986; Thylstrup e Fejerskov, 2001).

No presente estudo, não foram relatados efeitos colaterais significativos após o uso do gluconato de clorexidina a $0,12 \%$ no grupo Experimental, por 30 dias, exceto a observação de uma ligeira pigmentação da superfície dos elementos dentais, a qual não interferiu negativamente na estética, segundo relato de alguns pacientes. Possivelmente, isso ocorreu em função da baixa concentração e do período de tempo relativamente reduzido de uso da clorexidina. Estudos adicionais são necessários, a fim de avaliar se o uso desse protocolo, por longos períodos, não ocasionaria efeitos colaterais adicionais.

Em Ortodontia, observa-se que a clorexidina vem sendo empregada para redução dos níveis de microrganismos cariogênicos na cavidade bucal, sob a forma de bochecho, por vários autores (Amitha e Munshi, 1995; Gehlen et al., 2000; Auschill et al., 2005; Sari e Birinci, 2007; Lessa et al., 2007; Maruo et al. 2008).

0 efeito de uma solução com clorexidina a $0,2 \%$ (Hexidine) em pacientes portadores de aparelhos ortodônticos removíveis, utilizada duas vezes por dia, durante 14 dias, sobre os microrganismos presentes no biofilme dental foi avaliado por Amitha e Munshi (1995). Os autores concluíram que a terapia com gluconato de clorexidina a $0,2 \%$ foi efetiva na redução microbiana.

A influência de um enxaguatório bucal com clorexidina a $0,2 \%$ $\left(\right.$ Corsody $^{\circledR}$ ) foi avaliada durante a terapia com aparelho fixo por Gehlen et al. (2000). Contagens bacteriológicas com determinação de unidades formadoras de colônias, especialmente de $S$. mutans foram efetuadas e relacionadas aos índices de placa e gengival. Todos os parâmetros demonstraram diferenças significantes entre os grupos controle e experimental, tendo a solução de clorexidina a $0,2 \%$ reduzido significantemente os índices de placa e gengival, como também a recolonização bacteriana. 
Em 2005, Auschill et al. avaliaram a influência de uma solução de clorexidina a $0,2 \% \quad\left(\right.$ Chlorhexamed $\left.^{\circledR}\right)$ em pacientes que usaram um aparelho removível de acrílico especial durante 48 horas. A vitalidade do biofilme foi avaliada por meio de um corante específico, empregando um programa de imagem e a espessura do biofilme foi avaliada por meio de microscopia de varredura a laser. Essa solução reduziu significantemente a vitalidade do biofilme.

Lessa et al. (2007) avaliaram a contaminação da base de acrílico de aparelhos ortodônticos removíveis e a eficácia de duas soluções antimicrobianas, in vivo, por meio de estudo clínico randomizado. A análise microbiológica foi realizada por meio de cultura microbiana, a qual mostrou que a solução de cloreto de cetilpiridínio a 0,05\% (Cepacol ${ }^{\circledR}$ ) e a de gluconato de clorexidina a $0,12 \% \quad\left(\right.$ Periogard ${ }^{\circledR}$ ) reduziram sigificantemente o número de Streptococcus mutans comparados ao grupo que utilizou água esterilizada como controle. Os autores concluíram que embora o Cepacol ${ }^{\circledR}$ tenha sido mais eficaz que o controle, o Periogard ${ }^{\circledR}$ deveria ser indicado para a desinfecção de aparelhos ortodônticos removíveis, por ter mostrado uma redução significantemente maior na contaminação por Streptococcus mutans.

A solução de clorexidina a 0,2\% também foi avaliada por Maruo et al., em 2008, quanto à contagem de estreptococos e a massa de biofilme formada em disjuntores palatinos. Os pacientes que teriam seus aparelhos removidos foram divididos em dois grupos. Um grupo utilizou a clorexidina três vezes ao dia por uma semana, antes da remoção aparelho, e o outro não utilizou solução antimicrobiana. A contagem de unidades formadoras de colônias foi realizada por meio de cultura microbiana e a massa foi determinada pela diferença de peso do aparelho com e sem o biofilme aderido. A clorexidina reduziu significantemente a quantidade total de estreptococos, porém a massa não apresentou alterações entre os grupos testados.

Os resultados desses estudos, realizados com o emprego da técnica de cultura microbiana, evidenciaram a eficácia da clorexidina, em diferentes protocolos de aplicação sob a forma de bochechos, em pacientes portadores de aparelhos ortodônticos, o que também foi evidenciado no presente estudo, empregando a técnica de biologia molecular Checkerboard DNA-DNA Hibridization. 
0 protocolo de utilização do gluconato de clorexidina a $0,12 \%$, sob a forma de 2 bochechos diários de 30 segundos, por 30 dias, empregado no presente estudo, numericamente reduziu os níveis dos 4 microrganismos cariogênicos avaliados ( $S$. mutans, S. sobrinus, L. casei e L. acidophilus), evidenciando sua aplicabilidade do ponto de vista clínico, em Ortodontia. No entanto, houve redução estatisticamente significante apenas para os $S$. mutans $(p=0,02)$.

Resultados semelhantes também foram observados no estudo de Sari e Birinci (2007), que empregou a técnica de cultura microbiana. Esses autores avaliaram in vivo o efeito da solução com gluconato de clorexidina a $0,2 \%$ nas contagens de $S$. mutans e de lactobacilos, em pacientes com aparelho ortodôntico fixo. Saliva foi coletada logo após a montagem do aparelho e duas semanas depois, sem o uso da solução antimicrobiana, e no final da terceira e quarta semanas, com a realização de bochechos com solução de clorexidina duas vezes por dia. A contagem de unidades formadoras de colônias salivares aumentou significativamente para ambos os microrganismos, após a colocação do aparelho. No entanto, houve redução significante após a primeira semana de uso da solução com gluconato de clorexidina apenas para S. mutans. O mesmo não foi observado com relação aos lactobacilos pois, embora tenha ocorrido pequena redução numérica dos níveis salivares após 0 uso dos bochechos com clorexidina, essa redução não foi estatisticamente significante para esse microrganismo, o que está de acordo com o presente estudo, efetuado por meio de técnica de biologia molecular.

Como relatado por Emilson (1977), Kara et al. (2006) e Featherstone (2006), dentre os estreptococos do grupo mutans, a espécie $S$. mutans é a mais sensível à clorexidina, podendo esta ser usada para reduzir a quantidade desses microrganismos na cavidade bucal (Maltz et al.,1981; Amitha e Munshi, 1995; Menendez et al., 2005), o que foi evidenciado também no presente estudo. Por outro lado, os lactobacilos possivelmente apresentam uma menor sensibilidade à clorexidina, independente da concentração e da frequência de uso (Sari e Birinci, 2007).

Concordamos com Featherstone (2006), quando afirma que com o uso da clorexidina as bactérias podem não ser eliminadas, mas sim reduzidas, 
confirmando os resultados desse estudo com relação aos $S$. sobrinus, L. casei e L. acidophilus, após o uso dos bochechos com essa solução.

Além disso, acreditamos que a falta de evidência estatística na redução de $L$. casei e $L$. acidophilus pode ter sofrido a influência da localização geográfica desses microrganismos na estrutura do braquete, incluindo saliências e reentrâncias. Como já evidenciado na literatura, os Lactobacillus colonizam nichos ecológicos retentivos dos dentes (Loesche et al., 1984; Badet e Thebaud, 2008) e dos acessórios ortodônticos (Sakamaki e Bahn, 1968; Lundstrom e Krasse, 1987; Chang et al., 1999), que são sítios que dificultam o acesso do agente antimicrobiano. Além disso, quando os microrganismos se encontram em locais de difícil remoção inclusive pela ação mecânica da saliva e fluidos da cavidade bucal, mesmo que estes estejam mortos pela ação do clorexidina, o DNA pode persistir nesses locais por longos períodos de tempo. Dependendo da quantidade retida, esse DNA pode ser detectado pelas técnicas de biologia molecular, conforme salientado por Young et al. (2007).

Assim, outros estudos são necessários, envolvendo o uso de técnicas de biologia molecular e diferentes protocolos de uso da clorexidina, em diferentes concentrações e formas de aplicação (soluções ou géis), a fim de obter o controle adequado dos níveis de todos os microrganismos cariogênicos, em pacientes portadores de aparelho ortodôntico fixo. 
6 CONCLUSÃO

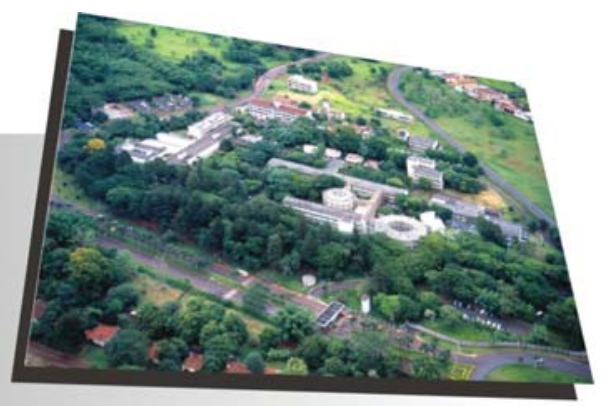




\section{ConCLUSÃo}

Considerando as condições específicas deste trabalho, com base nos resultados obtidos no estudo clínico randomizado com o uso a técnica Checkerboard DNA-DNA Hybridization, pôde-se concluir que:

- Todos os microrganismos cariogênicos avaliados (Streptococcus mutans, Streptococcus sobrinus, Lactobacillus casei e Lactobacillus acidophilus) foram detectados nas amostras oriundas dos bráquetes metálicos in vivo, no grupo Controle, com níveis mais elevados para os Streptococcus mutans e Streptococcus sobrinus $(p<0,01)$.

- O uso de bochechos com solução de gluconato de clorexidina a 0,12\% ocasionou redução numérica nos níveis de Streptococcus mutans, Streptococcus sobrinus, Lactobacillus casei e Lactobacillus acidophilus. No entanto, essa redução foi estatisticamente significante apenas para os Streptococcus mutans $(p=0,03)$.

- Os bochechos com solução de gluconato de clorexidina a 0,12\% podem ser úteis, na prática clínica, com a finalidade de reduzir os níveis de microrganismos cariogênicos, em pacientes portadores de aparelhos ortodônticos fixos. 


\section{REFERÊNCIAS}

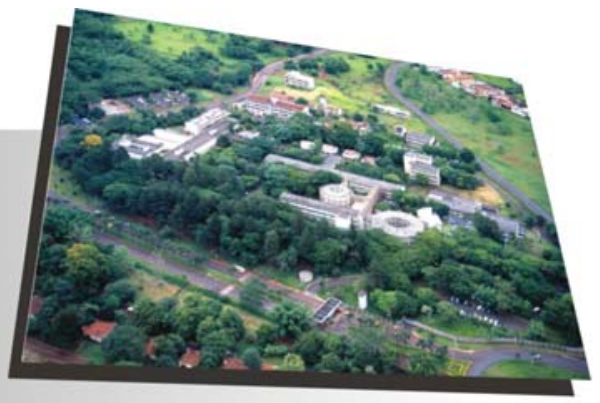




\section{REFERÊNCIAs*}

1. Ajdic D, McShan WM, McLaughlin RE, Savic G, Chang J, Carson MB, Primeaux C, Tian R, Kenton S, Jia H, Lin S, Qian Y, Li S, Zhu H, Najar F, Lai H, White J, Roe BA, Ferretti JJ. Genome sequence of Streptococcus mutans UA159, a cariogenic dental pathogen. Proc Natl Acad Sci 2002;99(22):14434-9.

2. Ahn SJ, Lim BS, Lee SJ. Prevalence of cariogenic streptococci on incisor brackets detected by polymerase chain reaction. Am J Orthod Dentofacial Orthop 2007; 131:736-41.

3. Ahn SJ, Lim BS, Yang HC, Chang Y-II. Quantitative analysis of the adhesion of cariogenic streptococci to orthodontic metal brackets. Angle Orthodontist. 2005; 75:666-71.

4. Ahn SJ, Kho HS, Kim K K,Nahm DS. Adhesion of Oral streptococci to Experimental Bracket Pellicles form Glandular Saliva. Am J Orthod Dentofacial Orthop 2003; 124: 198-205.

5. Anhoury P, Nathanson D, Hughes CV, Socransky S, Feres M, Chou LL. Microbial profile on metallic and ceramic bracket materials. Angle Orthodontist 2002; 72(4): 338-43.

6. Ai H, Lu HF, Liang HY, Wu J, Li RL, Liu GP, Xi Y. Influences of bracket bonding on mutans streptococci in plaque detected by real time fluorescence-quantitative polymerase chain reaction. Chin Med J (Engl). 2005 Dec 5;118(23):2005-10.

7. Alves P, Alviano W, Bolognese A, Nojima LI. Treatment protocol to control Streptococcus mutans level in a orthodontic patient with high caries risk. AM J Orthod Dentofacial Orthop 2008; 133:91- 94.

8. Amitha $H$, Munshi AK. Effect of chlorhexidine gluconato mouthwash on the plaque microflora in children using intra oral appliances. J Clin Pediatr Dent. 1995; 20:23-9.

9. Artun J, Brobakken BO. Prevalence of carious white spots after orthodontic treatment with multibonded appliances. Eur J Orthod. 1986;8(4):229-34.

10. Auschill TM, Hein M, Hellwig E, Follo M, Scullean A, Arweiler NB. Effect of two antimicrobials agents on early in situ biofilms formation. J Clin Periodontol. 2005; 32: $147-52$.

11. Badet $M C$, Richard $B$, Dorignac $G$. An in vitro study of the $\mathrm{pH}$-lowering potential of salivary lactobacilli associated with dental caries. J Appl Microbiol. 2001 Jun; 90(6):1015-8.

12. Badet C, Thebaud NB. Ecology of lactobacilli in the oral cavity: a review of literature. Open Microbiol J. 2008;2:38-48.

\footnotetext{
* De acordo com as Normas Internas do Programa de Pós-Graduação em Odontopediatria da FORP/USP (2003).
} 
13. Bagatin-Rossi CR. Formação de biofilme e corrosão em aparelhos disjuntores de Haas, com e sem utilização de agente antimicrobiano: estudo in situ. [dissertação]. Ribeirão Preto: FORP - Univ. de São Paulo; 2007.

14. Batoni G, Pardini M, Giannotti A, Ota F, Giuca MR, Gabriele M, Campa M, Senesi $S$. Effect of removable orthodontic appliances on oral colonization by mutans streptococci in children. Eur J Sci 2001;109:388-92.

15. Berkowitz RJ. Causes, treatment and prevention of early caries: a microbiologic perspective. J Can Dent Assoc 2003;69(5):304-7b.

16. Bjerklin K, Garskog B, Ronnerman A. Proximal caries increment in connection with orthodontic treatment with orthodontic treatmentwith removable appliances. $\mathrm{Br}$ J Orthod 1983;10:21-4.

17. Brightman LJ, Terezhalmy GT, Greenwell H, Jacobs M, Endlow DH. The effects of a 0.12 per cent chlorhexidine gluconate mouthrinse on orthodontic patients aged 11 through 17 with established gingivitis. Am J Orthod Dentofacial Orthop.1991; 100: 324-329.

18. Brusca M, Chara O,Sterin-Borda L, Rosa A. Influence of different orthodontic brackets on adherence of microorganism in vitro. Angle Orthodontis 2007; 77: 331-336.

19. Chang HS, Walsh LJ, Freer TJ. The effect of orthodontic treatment on salivary flow, pH, buffer capacity, and levels of mutans streptococci and lactobacilli. Aust Orthod 1999;15(4):229-34.

20. Consolaro A, Consolaro M. Controvérsias na Ortodontia \& Atlas de Biologia da Movimentação Dentária. 1 ed: Dental Press; 2008.

21. Costa Neto PLO. Estatística. 2a ed. São Paulo: Ed. Edgard Blucher; 2002.

22. Denton GW. Chlorhexidine. In: Block SS, editors. Disinfction, sterization, preservations. $4^{\text {th }}$ ed. Philadelphia:Ed. Lea \& Febiger; 1991.p.274-89.

23. Derks A, Frencken J, Bronkhorts E, Kuijpers-Jatman A, Katsaros C. Effect of Clorhexidine varnish application on mutans streptococci counts in orthodontic patients. Am J Orthod Dentofacial Orthop 2008;133:435-439.

24. De Soet JJ, Toors FA, De Graaff J. Acidogenesis by oral streptococci at different pH values. Caries Res $1989 ; 23: 14-17$.

25. De Soet JJ, Holbrook WP, van Amerongen WE, Schipper E, Homburg $\mathrm{CH}$, de Graaff J. Prevalence of Streptococcus sobrinus in relation to dental caries in children from Iceland and The Netherlands. ASDC J Dent Child. 1990 SepOct; 57(5):337-42.

26. Dills SS, Olshan AM, Goldner S, Brogdon C. Comparison of the antimicrobial capability of an abrasive paste and chemical-soak denture cleaners. J Prosthet Dent. 1988; 60(4):467-70. 
27. Emilson CG. Susceptibility of various microorganisms to chorhexidine. Scand J Dent Res. 1977; 85: 255-65.

28. Faltermier A, Burgüers R, Rosentritt. Bacterial adhesion of Streptococcus mutans to esthetic materials. Am J Orthop 2008; 133: S99-103.

29. Fardal O, Turnbull RS. A review of the literature on use of chlorhexidina in dentistry. J ournal of America Dental Association 1986; 112: 863.

30. Featherstone JDB. Delivery challenges for fluoride, chlorhexidine and xylitol. BMD Oral Health 2006; 15;6 Suppl 1:S8.

31. Feinberg AP, Vogelstein B. A technique for radiolabeling DNA restriction endonuclease fragments to high specific activity. Anal Biochem. $1983 \mathrm{Jul}$ $1 ; 132(1): 6-13$.

32. Fejerskov O, Kidd E. Cárie Dentária. A doença e seu tratamento clínico. São Paulo: Ed Santos, 2005.

33. Filoche SK, Soma KJ, Sisson CH. Caries-related plaque microcosm biofilms developed in microplates. Oral Microbiology Immunology 2007:22:73-79.

34. Fletcher RH, Fletcher SW, Wagner EH. Epidemiologia clínica: elementos essenciais. 3a rd. Porto Alegre: Artmed; 2002.

35. Fontana M, Zero DT. Assessing patients' caries risk. J Am Dent Assoc 2006; 137:1231-1239.

36. Friedman M, Harari D, Raz H, Golomb G, Brayer L. Plaque inhibition by sustained release of chlorhexidine from removable appliances. J Dent Res 1985; 64(11): 1319-1321.

37. Fujiwara T, Sasada E, Mima N, Ooshima T. Caries prevalence and salivary mutans streptococci in 0-2- year-old children of Japan. Community Dent Oral Epidemiol 1991;19:151-4.

38. Gehlen I, Netuschill L, Georg T, Reich E, Berg R, Katsaros. The influence of a $0.2 \%$ Chlorhexidine Mouthrinse on Plaque Regrowth in the Orthodontic Patients. J Orofac Orthop 2000; 61: 138-148.

39. Gibbons RJ, Cohen I, Hay DI. Strains of Streptococcus mutans and Streptococcus sobrinus attach to different pellicle receptors. Infect Immun 1986; 52:555-561.

40. Gizani S, Papaioannou W, Haffajee AD, Kavvadia K, Quirynen M, Papagiannoulis $\mathrm{L}$. Distribution of selected cariogenic bacteria in five different intra-oral habitats in young children. Int J Paediatr Dent. 2008.

41. Gjermo P. Chlorhexidine in dental practice. J Clin Periodontol. 1974; 1: 143-52.

42. Gorelick L, Geiger AM, Gwinnett AJ. Incidence of white spot formation after bonding and banding. Am J Orthod. 1982 Feb;81(2):93-8. 
43. Haffajee $A D$, Socransky SS, Patel MR,Song $X$. Microbioal Complexes in supragingival plaque. Oral Microbiology Immunology 2008; 23:196-205.

44. Hardie JM. Oral Streptococci. In: Bergey DH. Bergey's manual of systematic bacteriology. Baltimore: Williams \& Wilkins; 1986. v.2, p.1054- 63.

45. Hidalgo $E$, Dominguez C. Mechanisms underlying chlorhexidine induced citotoxity. Toxicol in Vitro 2001;15: 271-6.

46. Höfling JF, Spolidório DMP, Pereira CV, Rosa EAR, Moreira D. Presença de Streptococcus mutans e Streptococcus mutans associado a Streptococcus sobrinus em escolares de diferentes classes sócio-econômicas e sua relação com a atividade cariogênica dessas populações. Rev Odontol Univ São Paulo 1999; 13:173-80.

47. I oannou I, Dimitriadis N, Papadimitriou K, Sakellari D, Vouros I, Konstantinidis A. Hand instrumentation versus ultrasonic debridement in the treatment of chronic periodontitis: a randomized clinical and microbiological trial. J Clin Periodontol. 2009 Feb;36(2):132-41.

48. Jordan C, Leblanc DJ. Influences of orthodontics appliances on oral populations of mutans streptococci. Oral Microbiol Immunol 2002;17:65-71.

49. Kara D, Luppens SBI, ten Cate JM. Differences between single and dual species biofilms of Streptococcus mutans and Veillonella parvula in growth, acidogenicity and susceptibility to chlorhexidine. Eur j Oral Sci 2006; 114:58-63.

50. Kohler B, Bjarnason S. Mutans streptococci, lactobacilli and caries prevalence in 11- and 12-year-old Icelandic children. Community Dent Oral Epidemiol $1987 ; 15: 332-335$.

51. Kohler B, Andreen I, Jonsson B. The earlier the colonization by mutans streptococci, the higher the caries prevalence at 4 years of age. Oral Microbiol Immunol 1988; 3:14-7.

52. Kolstad R, Petti H. A safe, effective germicide-deodorizer for removable appliances. J Clin Orthod 1983; 17:56-7.

53. Lessa FC, Enoki C, Ito IY, Faria G, Matsumoto MA, Nelson-Filho P. In-vivo evaluation of the bacterial contamination and disinfection of acrylic baseplates of removable orthodontic appliances. Am J Orthod Dentofacial Orthop 2007 Jun; 131(6): 705.e11-7.

54. Leung NM, Chen R, Rudney JD. Oral bacteria in plaque and invading bucal cells young orthodontic patients. Am J Orthod Dentofacial Orthop. 2006; 130: 698.e18.

55. Lim BS, Lee S, Lee J, Ahn SJ. Quantitative analysis of adhesion of cariogenic streptococci to orthodontic raw materials. Am J Orthod Dentofacial Orthop 2008; 133: 882-8. 
56. Lindquist B, Emilson CG. Colonization of Streptococcus mutans and Streptococcus sobrinus genotypes and caries development in children to mothers harboring both species. Caries Res 2004;38:95-103.

57. Lindquist B, Emilson CG. Dental location of Streptococcus mutans and Streptococcus sobrinus in humans harboring both species. Caries Res 1991;25: 146-152.

58. Lo BA, Di Marco R, Milazzo I, Nicolosi D, Calì G, Rossetti B, Blandino G. Microbiological and clinical periodontal effects of fixed orthodontic appliances in pediatric patients. New Microbiol. 2008 Apr;31(2):299-302.

59. Loe H, Schiott CR, Glavind L, Kaning T. Two years oh use of chlorhexidine in man. General design and effects. J Periodont Res. 1976; 11:135-4.

60. Loesche WJ. Role of Streptococcus mutans in human dental decay. Microbiol Rev 1986;50:353-80.

61. Loesche WJ, Eklund S, Earnest R, Burt B. Longitudinal investigation of bacteriology of human fissure decay: epidemiological studies in molars shortly after eruption. Infect Immun 1984;46(3):765-772.

62. Lopes JL, Saba-Chujfi E, Fernandes PA, Saba MEC. A utilização do digluconato de clorexidina nos últimos anos e suas perspectivas futuras. Rev Paulista de Odontologia 1992; 4:16-20.

63. Lundstrom F, Krasse B. Streptococcus mutans and lactobacilli frequency in orthodontic patients: the effect of chlorhexidine treatments. Eur J Orthod $1987 ; 9(2): 109-16$.

64. Magno AFF, Enoki C, Ito IY, Matsumoto MAN, Faria G, Nelson-Filho P. In vivo evaluation of contamination of Super Slick elastomeric rings by Streptococcus mutans in orthodontic patients. Am J Orthod Dentofacial Orthoped 2008; 133(4 suppl):S104-9.

65. Maltz M, Zicket I, Krasse B. Effects of different caries preventive measures in children highly infected mutans streptococci. Scand J Dent Res 1981; 89: 445-9.

66. Martins-Ortiz MF, Freitas PZ, Nelson-Filho P, Consolaro A. Por que se preocupar com a higienização dos aparelhos? Dental Press Orthodon Ortop Facial 2004;9: 30-32.

67. Maruo IT, Rosa EAR, Maruo H, Tanaka O, Guariza F, Ignácio AS, Camargo ES. Effects of chlorhedine mouth rinse on Streptococci counts of tooth-tissue-borne palatal expander biofilm. Orthop Craniofac Res 2008; 11: 136-142.

68. Matarazzo F, Figueiredo LC, Cruz SE, Faveri M, Feres M. Clinical and microbiological benefits of systemic metronidazole and amoxicillin in the treatment of smokers with chronic periodontitis: a randomized placebo-controlled study. J Clin Periodontol. 2008 Oct;35(10):885-96. 
69. Mattingly JA, Sauer GJ, Yancey JM, Arnold RR. Enhancement of Streptococcus mutans colonization by direct bonded orthodontic appliances. J Dent Res 1983; 62: 1209-11.

70. McNeill K, Hamilton IR. Acid tolerance response of biofilm cells of Streptococcus mutans. FEMS Microbiol Lett 2003;221:25-30.

71. Menendez A, Li F, Michalek SM, Kirk K, Makhija SK, Childers NK. Comparative analysis of the antibacterial effects of combined mouthrinses on Streptococcus mutans. Oral Microbiol Immunol 2005; 20: 31-4.

72. Moraes SR, Siqueira Júnior JF, Colombo AP, Rôças IN, Ferreira MCS, Domingues RMCP. Comparison of the effectiveness of bacterial culture, 16S rDNA directed polymerase chain reaction, and checkerboard DNA-DNA hybridization for detection of Fusobacterium nucleatum in endodontic infections. J. Endod 2002; 28: 86-9.

73. Moshrefi A. Chlorhexidine. J West Soc Periodontol Periodontal Abstr 2002; 50:59.

74. Naranjo AA, Triviño ML, Jaramillo A, Betancourth $M$, Botero JE. Changes in the subgingival microbiota and periodontal parameters before and 3 months after bracket placement. Am J Orthodontics and Dentofacial Orthopedics 2006; 130:275.e17-275.e22.

75. Nascimento C, Barbosa RE, Issa JP, Watanabe E, Ito IY, de Albuquerque Junior RF. Use of checkerboard DNA-DNA hybridization to evaluate the internal contamination of dental implants and comparison of bacterial leakage with cast or pre-machined abutments. Clin Oral Implants Res. 2009 Feb 21.

76. Olympio KP, Bardal PA, de M Bastos JR, Buzalaf MA. Effectiveness of a chlorhexidine dentifrice in orthodontic patients: a randomized-controlled trial. J Clin Periodontol. 2006; 33(6): 421-6.

77. Papaioannou W, Gizani S, Nassika M, Kontou E, Nakou M. Adhesion of Streptococcus mutans to different types of brackets. Angle Orthodontist 2007; 77: 1090-1095.

78. Parson JC. Chemoterapy of dental plaque - a review. J Periodontol 1974; 45: 177-86.

79. Peixoto, ITA. Avaliação de protocolos clínicos para a desinfecção de aparelhos ortodônticos removíveis (cultura microbiana e MEV). [dissertação]. Ribeirão Preto: FORP - Univ. de São Paulo; 2007.

80. Rolla G, Melsen B. The mechanism of the plaque inhibition by chlorhexidine. J Dent Res 1975; 54:57-62.

81. Rolla G, Loe H, Schiott CR. Retention of chlorhexidine in the human oral cavity. Arch oral Biol. 1971; 16: 1109-16.

82. Rosen S, Lenney WS, O'Malley JE. Dental caries in gnotobiotic rats inoculated with Lactobacillus casei. J Dent Res. 1968 May-J un; 47(3):358-63. 
83. Rosenbloom RG, Tinanoff N. Salivary Streptococcus mutans levels in patients before, during, and after orthodontic treatment. Am J Orthod Dentofacial Orthop. 1991; 100:35-7.

84. Rupf S, Merte K, Eschrich K, Kneist S. Streptococcus sobrinus in children and its influence on caries activity. Eur Arch Paediatr Dent 2006; 7:17-22.

85. Ruviere DB, Ito IY, Leonardo MR, Silva LAB, Nelson-Filho P. Assessment of the microbiota in root canals of human primary teeth by checkerboard DNA-DNA hybridization. J Dent Child, 2007;74(2):118-23.

86. Saito K, Hayakawa T, Kawabata R, Meguro D, Kasai K. In vitro antibacterial and cytotoxicity assessments of an orthodontic bonding agent containing benzalkonium chloride. Angle Orthod. 2009;79(2):331-7.

87. Sakamaki ST, Bahn AN. Effect of orthodontic banding on localized oral lactobacilli. J Dent Res 1968:47(2):275-9.

88. Sandham HJ, Nadeau L, Phillips HI. The effect of chlorhexidine varnish treatment on salivary mutans streptococcal levels in child orthodontic patients. J Dent Res. 1992 Jan; 71(1):32-5.

89. Sari E, Birinci I. Microbiological Evaluation of $0.2 \%$ clorhexidine Gluconate mouth Rinse in the Orthodontics patients. Angle Orthodontis 2007; 77: 881-884.

90. Seki M, Yamashita $Y$, Shibata $Y$, Torigoe $H$, Tsuda $H$, Maeno M. Effect of mixed mutans streptococci colonization on caries development. Oral Microbiol Immunol 2006;21:47-52.

91. Silness J, Loe H. Periodontal disease in pregnancy. II. Correlation between oral hygiene and periodontal condition. Acta Odontol Scand. 1964 Feb;22:121-35.

92. Silveira E. Meio século de história. Publicação de primeiro artigo sobre DNA completa 50 anos. Jornal UNESP 2003 abr n.176.

93. Siqueira JF Jr, Rôças IN. The microbiota of acute apical abscesses. J Dent Res. 2009;88(1):61-5.

94. Siqueira Júnior JF, Rôças IN, Souto R, Uzeda M, Colombo AP. Checkerboard DNADNA hybridization analysis of endodontic infections. Oral Surg Oral Med Oral Pathol Oral Radiol Endod 2000; 89: 744-8.

95. Smiech-Slomkowska G, Jablonska-Zrobek J. The effect of oral health education on dental plaque development and the level of caries-related Streptococcus mutans and Lactobacillus spp. Eur J Orthod. 2007;29(2):157-60.

96. Smith GL, Socransky SS, Smith CM. Rapid method for the purification of DNA from subgingival microorganisms. Oral Microbiol Immunol. 1989 Mar;4(1):47-51.

97. Socransky SS, Manganiello SD. The oral microbiota of man from birth to senility. J Periodontol. 1971 Aug;42(8):485-96. 
98. Socransky SS, Smith CL, Martin L, Paster BJ, Dewhirts FE, Levin A E. "Checkerboard" DNA-DNA Hybridization. Biotechniques 1994; 17: 788-790.

99. Sockransky SS, Haffage AD, Smith C, Martin L, Haffage JA. Uzel NG, Goodson JM. Use 0 checkerboard DNA-DNA hybridization to study complex microbial ecosystems. Oral Microbiology I mmunology 2004; 19:352-362.

100. Sreenivasan PK, Gaffar A. Antiplaque biocides and bacterial resistence: a review. J Clin Periodontol. 2002; 29:965-74.

101. Steinberg D, Eyal S. Initial biofilms formation of Streptococcus sobrinus on various orthodontics appliances. Journal of Oral Rehabilitation 2004; 31:1041-5.

102. Straetemans MM, van Loveren C, de Soet JJ, de Graaff J, ten Cate JM. Colonization with mutans streptococci and lactobacilli and the caries experience of children after the age of five. J Dent Res. 1998 Oct;77(10):1851-5.

103. Sudjalim TR, Woods MG, Manton DJ, Reynolds EC. Prevention of demineralization around orthodontic brackets in vitro. Am J Orthod Dentofacial Orthop. 2007; 131(6): 705.e1-9.

104. Tanzer JM, Livingston J, Thompson AM. The microbiology of primary dental caries in humans. J Dent Educ. 2001 Oct; 65(10):1028-37.

105. Teles RP, Bogren A, Patel M, Wennstrom J L, Socransky SS, Haffajee AD. A threeyear prospective study of adult subjects with gingivitis II: microbiological parameters. J Clin Periodontol. 2007 Jan; 34(1): 7-17.

106. Thylstrup A, Fejerskov O. Cariologia Clínica. 2nd ed. São Paulo: Editora Santos; 2001.

107. Vianna ME, Horz HP, Conrads G, Feres M, Gomes BP. Comparative analysis of endodontic pathogens using checkerboard hybridization in relation to culture. Oral Microbiol Immunol. 2008 Aug;23(4):282-90.

108. Young G, Turner S, Davies JK, Sundqvist G, Figdor D. Bacterial DNA persists for extended periods after cell death. J Endod. 2007 Dec;33(12): 1417-20.

109. Youravong N, Teanpaisan R, Chongsuvivatwong V, Geater AF, Dahlen G. Microbiology in toothbrush samples from children exposed to lead in southern Thailand. Acta Odontol Scand. 2007 Feb; 65(1):22-8. 
Anexo

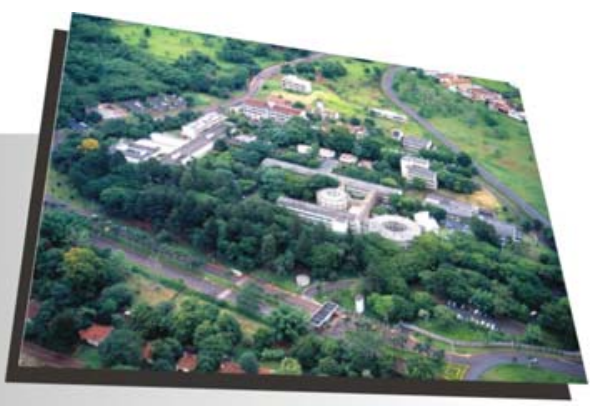




\title{
Anexo
}

\author{
UNIVERSIDADE DE SÃO PAULO \\ FACULDADE DE ODONTOLOGIA DE RIBEIRÃO PRETO \\ COMITÊ DE ÉTICA EM PESQUISA \\ Avenida do Café, $s / n^{\circ}$ - Telefone: (016) 3602-3963 \\ 14040-904 - Ribeirão Preto - SP - Brasil \\ Fax: (016) 3633-0999
}

OF.CEP/028/FORP

Senhor Professor,

Ref.: Processo no 2008.1.163.58.8

CAAE n'0 0013.0.138.000-08

A pedido da Profa. Dra. Simone Cecílio Hallak Regalo, Coordenadora do Comitê de Ética em Pesquisa desta Faculdade, informamos que o referido Comitê, em sua $86^{\prime}$ Sessão, realizada no dia 13 de março de 2008, deliberou aprovar o Projeto de Pesquisa envolvendo seres humanos, intitulado: "Avaliação da contaminação microbiana de aparelhos ortodônticos, com e sem utilização de agente antimicrobiano, pela técnica Checkerboard DNA-DNA Hybridization e quantificaçạo de Endotoxina (LPS) por meio do teste Limulus Amebo cyte Lysate", a ser desenvolvido por Vossa Senhoria, na Faculdade de Odontologia de Ribeirão Preto, devendo o atestado para publicação final ser expedido pelo Comitê de Ética em Pesquisa, após a entrega e aprovação do Relatório Final pelo referido Comitê.:

$\mathrm{Na}$ oportunidade, lembramos da necessidade de entregar na Secretaria do Comitê, com o formulário preenchido pelo pesquisador responsável, o Relatório Parcial no dia $\mathbf{3 0}$ de março de 2009 e o Relatório Final no dia $\mathbf{3 0}$ de março de 2010.

Atenciosamente,

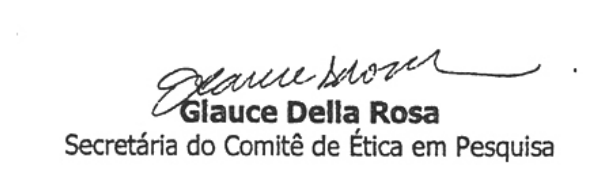

Ilmo. Sr.

Prof. Dr. PAULO NELSON FILHO

Professor Titular do Deppartamento de Clínica Infantil, Odontologia Preventiva e Social - FORP/USP GDR/gdr 


\section{AUTORI ZAÇÃo PARA RePROduÇÃo}

Autorizo a reprodução e/ou divulgação total ou parcial da presente obra, por qualquer meio convencional ou eletrônico, desde que citada a fonte.

\section{Lourdes Yanissely García Olmedo}

Universidade de São Paulo

Faculdade de Odontologia de Ribeirão Preto

Departamento de Clínica Infantil, Odontologia Preventiva e Social

Avenida do Café, s/n - CEP 14040-904

Ribeirão Preto - SP

2009 